\title{
Dynamical mechanisms linking Indian monsoon precipitation and the circumglobal teleconnection
}

\author{
Jonathan D. Beverley ${ }^{1,2}$ (1) $\cdot$ Steven J. Woolnough ${ }^{3}$ (1) $\cdot$ Laura H. Baker $^{3}$ (i) - Stephanie J. Johnson ${ }^{4}$. \\ Antje Weisheimer ${ }^{4,5}$ (1) Christopher H. O'Reilly ${ }^{5}$
}

Received: 16 October 2020 / Accepted: 24 May 2021 / Published online: 27 June 2021

(c) The Author(s) 2021

\begin{abstract}
The circumglobal teleconnection (CGT) is an important mode of circulation variability, with an influence across many parts of the northern hemisphere. Here, we examine the excitation mechanisms of the CGT in the ECMWF seasonal forecast model, and the relationship between the Indian summer monsoon (ISM), the CGT and the extratropical northern hemisphere circulation. Results from relaxation experiments, in which the model is corrected to reanalysis in specific regions, suggest that errors over northwest Europe are more important in inhibiting the model skill at representing the CGT, in addition to northern hemisphere skill more widely, than west-central Asia and the ISM region, although the link between ISM precipitation and the extratropical circulation is weak in all experiments. Thermal forcing experiments in the ECMWF model, in which a heating is applied over India, suggest that the ISM does force an extratropical Rossby wave train, with upper tropospheric anticyclonic anomalies over east Asia, the North Pacific and North America associated with increased ISM heating. However, this eastward-propagating branch of the wave train does not project into Europe, and the response there occurs largely through westward-propagating Rossby waves. Results from barotropic model experiments show a response that is highly consistent with the seasonal forecast model, with similar eastward- and westward-propagating Rossby waves. This westward-propagating response is shown to be important in the downstream reinforcement of the wave train between Asia and North America.
\end{abstract}

Keywords Seasonal forecasting $\cdot$ Circumglobal teleconnection $\cdot$ Indian monsoon $\cdot$ Relaxation experiment $\cdot$ Barotropic model

Jonathan D. Beverley

j.d.beverley@exeter.ac.uk

1 Department of Meteorology, University of Reading, Earley Gate, Reading RG6 6ET, UK

2 Present Address: College of Engineering, Mathematics and Physical Sciences, University of Exeter, Exeter EX4 4QE, UK

3 National Centre for Atmospheric Science, Department of Meteorology, University of Reading, Earley Gate, Reading RG6 6ET, UK

4 ECMWF, Shinfield Park, Reading RG2 9AX, UK

5 Department of Physics, National Centre for Atmospheric Science (NCAS), University of Oxford, Oxford OX1 3PU, UK

\section{Introduction}

The circumglobal teleconnection (CGT) is a prominent wavenumber-5 teleconnection mechanism that manifests in the northern hemisphere summer. First identified by Ding and Wang (2005), it has centres of action over west-central Asia, east Asia, the North Pacific, North America and northwest Europe, where the upper-level pressure variations are nearly all in phase (Fig. 1). It is associated with significant temperature and precipitation anomalies in these regions (see Figures 7 and 9 from Ding and Wang 2005), and so accurate representation of this mechanism in seasonal forecasting systems could be an important source of subseasonal to seasonal forecast skill.

The convective heat source over the Bay of Bengal and the Indian summer monsoon (ISM) region and its associated upper-tropospheric divergence can serve as a Rossby wave source. Ding and Wang $(2005,2007)$ hypothesised 
Fig. 1 The August CGT wave train: correlation between ERAInterim $200 \mathrm{hPa}$ geopotential height at the base point (the $\mathrm{D} \& \mathrm{~W}$ region, $35^{\circ}-40^{\circ} \mathrm{N}, 60^{\circ}$ $-70^{\circ} \mathrm{E}$ ) and $200 \mathrm{hPa}$ geopotential height elsewhere. The boxes indicate the geopotential height indices used for the analysis in Sect. 3 (listed in Table 2)

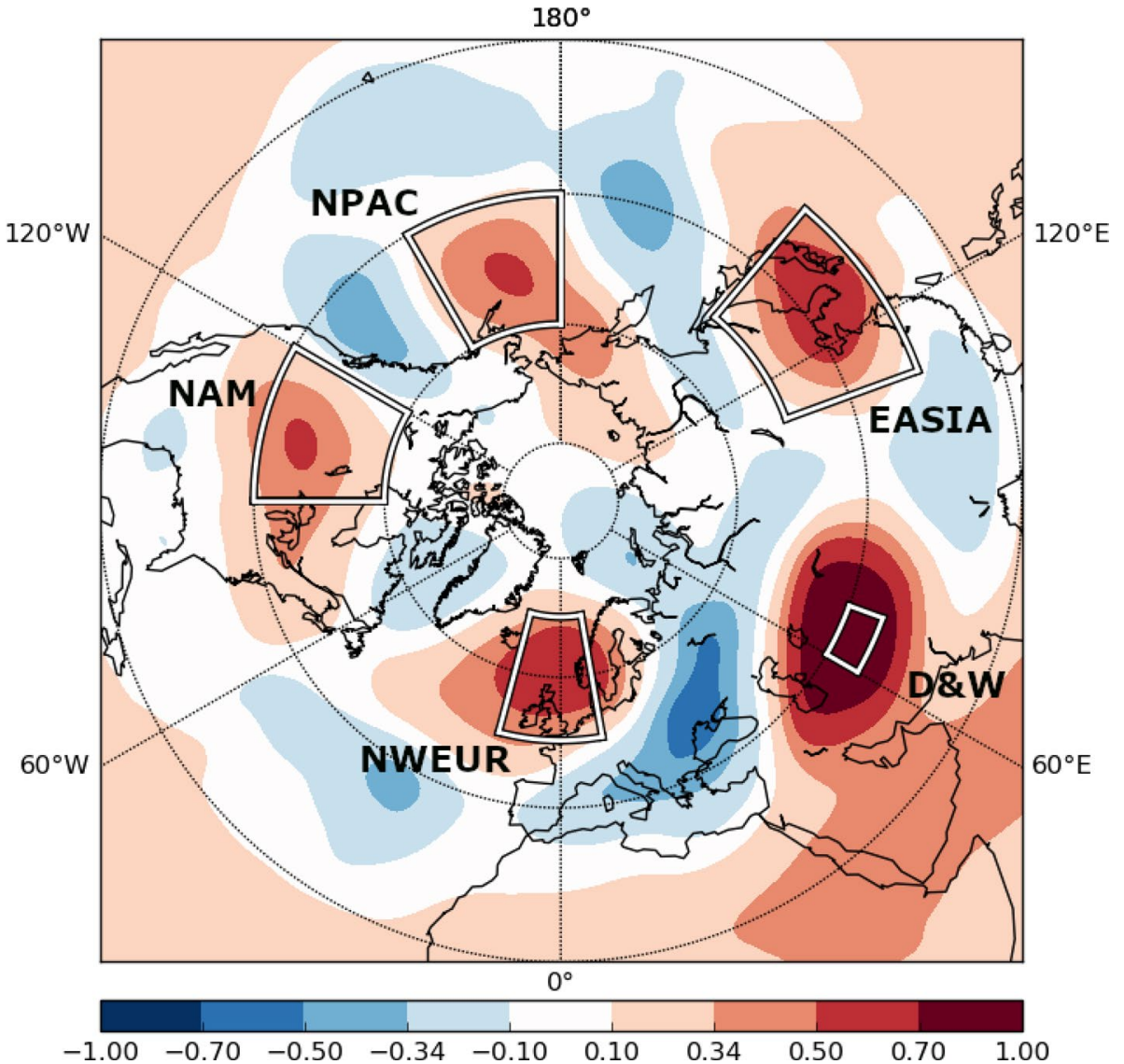

that the interaction of ISM precipitation with the extratropical circulation plays an important role in the maintenance of the CGT. A number of studies have found that strong ISM precipitation is associated with anticyclonic anomalies over west-central Asia and east Asia, near Japan (Wang et al. 2001; Wu and Wang 2002). The propagation of Rossby waves from the jet exit region over northwest Europe to Asia results in the development of an anomalous upper-level high over west-central Asia. The easterly anomalies to the south of this high strengthen the monsoon easterly vertical shear over northern India, which enhances the convection in this region. This convection and associated diabatic heating in turn excites a Rossby wave response, similar to those of Gill (1980) and Rodwell and Hoskins (1996), which reinforces the west-central Asian high. This then enhances downstream circulation anomalies through the propagation of these waves along the waveguide (the westerly jet) (Liu and Wang 2013). Linked to this mechanism, Lau and Weng (2002) found that North America summer precipitation variability is connected to a wave train that originates in Asia. Lau et al. (2004) named this the "Tokyo-Chicago Express".

Related to these mechanisms is the Silk Road Pattern (SRP), which is associated with stationary Rossby waves trapped in the Eurasian jet stream (Lu et al. 2002; Enomoto et al. 2003). Stephan et al. (2019) examined the decadal variability of the SRP and identified a positive feedback loop between the SRP and vertical motion over India and the Mediterranean, whereby more coherent monsoon precipitation leads to increased descent over the Mediterranean region, via the monsoon-desert mechanism (Rodwell and Hoskins 1996), which subsequently induces ascent over India following the propagation of Rossby waves along the Asian jet. Ding and Wang (2005) showed that the Tokyo-Chicago Express and the SRP can be viewed as local manifestations of the CGT (Chen and Huang 2012; Kosaka et al. 2012; Hong and Lu 2016).

Despite being a prominent mode of northern hemisphere summertime circulation variability, the ECMWF seasonal forecast model struggles to accurately represent some aspects of the CGT. Beverley et al. (2019) showed that the ECMWF model has a generally weak representation of the CGT, along with poor skill for geopotential height in the location of the centres of action of the CGT, including over west-central Asia and northwest Europe. Several potential causes of this weak representation were proposed-these include propagation errors, such as a northward shifted model jet bias, which will impact on Rossby wave propagation in the model, and forcing errors, such as errors in the Rossby wave source (RWS, Sardeshmukh and Hoskins 1988) over west-central Asia and a 
weak link between ISM precipitation and the extratropical circulation.

In this paper, the following questions will be addressed:

- What impact does heating associated with the ISM have on the extratropical circulation, and what is its role in forcing the CGT?

- How does the Indian monsoon influence the circulation over Europe?

- What are the main reasons for the lack of skill in the representation of the CGT in the ECMWF model?

To answer these questions, a number of different types of experiment will be presented. Firstly, to further understand the evolution and potential causes of the above errors, results from several relaxation experiments are shown, in which the circulation over west-central Asia, northwest Europe and the ISM region is corrected towards reanalysis. Based on results from these experiments, a further set of experiments in the ECMWF model were carried out in which a thermal forcing was applied in the ISM region to explore the northern hemisphere response to variations in heating associated with the monsoon.

In addition to experiments in the coupled seasonal forecast model, we also present results using a linear barotropic model. This type of idealised model can be a useful tool to help understand the propagation of Rossby waves under different conditions. For example, Shaman and Tziperman (2007) showed that El Niño can affect the strength of the Indian monsoon via a westward-propagating Rossby wave response, and O'Reilly et al. (2018) demonstrated that the summertime Euro-Atlantic circulation is largely forced by precipitation anomalies in the eastern tropical Pacific, with contributions from both eastward- and westward-propagating Rossby waves.

The rest of the paper is arranged as follows. In Sect. 2 we outline the data, models and methods used, including an overview of the ECMWF and barotropic models, as well as details of the relaxation and thermal forcing techniques. Results from relaxation experiments are presented in Sect. 3, followed by thermal forcing experiments in Sect. 4 and barotropic model experiments in Sect. 5. A summary and the main conclusions can be found in Sect. 6 .

\section{Data, models and methods}

\subsection{Seasonal forecast model}

\subsubsection{Model details}

The seasonal forecast model used is version Cy41r1 of the European Centre for Medium-Range Weather Forecasts
(ECMWF)'s Integrated Forecasting System model (IFS), coupled to the Nucleus for European Modelling of the Ocean model (NEMO). This version of the atmospheric model is a more recent one than in the former operational model, System 4 (Cy36r4, Molteni et al. 2011), but older than in the current seasonal forecast model, SEAS5 (Cy43r1, Johnson et al. 2019). The horizontal spectral resolution of the atmospheric model (T255) is the same as System 4 and corresponds to a grid length of approximately $80 \mathrm{~km}$. The atmospheric model was run with 60 vertical levels, with the model top at $0.01 \mathrm{hPa}$, while the ocean model has a resolution of approximately $1^{\circ}$ with 42 vertical levels (Beverley et al. 2019).

The different number of vertical levels used here $(60$ compared to 91 in Beverley et al. 2019) is a requirement of performing relaxation experiments, as there needs to be the same number of levels in the model run as there are in the reference dataset (ERA-Interim), to enable the relaxation to take place on all levels. This is the only difference between the model used in these experiments and the model analysed in Beverley et al. (2019), and the control integration used here has similar performance to the 91 level model of Beverley et al. (2019).

Experiments were performed using the ECMWF ERAInterim (Dee et al. 2011) and ORAS4 (Balmaseda et al. 2013) reanalyses for initialisation of the atmosphere and ocean, respectively. They are initialised on 1st May for the period 1981-2014 and run for four months, therefore covering the boreal summer season of June-August (JJA) and much of the ISM season. The relaxation experiments presented here have 25 ensemble members, whereas the thermal forcing experiments have 5 members.

\subsubsection{Relaxation technique}

In Sect. 3, relaxation experiments in the ECMWF model are performed in order to further understand the CGT mechanism and errors associated with its representation in the model. Relaxation of the atmosphere in a model is a well-established technique for analysing model performance and deficiencies. The technique (also known as nudging) involves relaxing the model temperature, winds and humidity-based variables towards a reference state (usually reanalysis) throughout the length of a forecast in a pre-defined region. It has previously been used to help understand the impact of tropical biases on the extratropical circulation (Ferranti et al. 1990; Jung et al. 2010a), to identify possible sources of predictability (Klinker 1990) as well as to investigate the origin of atmospheric circulation anomalies in the northern hemisphere in specific extreme seasons (Jung et al. 2010b; Douville et al. 2011; Watson et al. 2016).

The relaxation of variable $X$ is carried out through the addition of an extra term, $X_{\text {relax }}$, to the ECMWF model: 


$$
\frac{\partial X}{\partial t}=S+X_{\text {relax }}
$$

where $S$ represents the advective tendencies and sources and sinks due to physical parametrisations in the model, and where $X_{\text {relax }}$ is of the form:

$X_{\text {relax }}=-\gamma(\phi, \lambda) \frac{X_{\mathrm{old}}-X_{\text {ref }}}{\tau}$,

where $X_{\text {old }}$ is the model variable being relaxed, $X_{\text {ref }}$ is the reference state towards which the model is drawn (in this case ERA-Interim), $\gamma(\phi, \lambda)$ is a function that smooths the transition from relaxed to non-relaxed regions and $\tau$ is the relaxation timescale which has a value of $2.75 \mathrm{~h}$. The relaxation is applied every time step, with $X_{\text {ref }}$ updated by linear interpolation between the 6-hourly data from ERA-Interim. Further details about the relaxation technique can be found in the "Appendix" and details of the individual experiments in Sect. 3.

\subsubsection{Thermal forcing technique}

In Sect. 4, we perform thermal forcing experiments in the ECMWF model in which we impose a heating in a specific region through the addition of an extra temperature tendency, $\mathcal{H}$, at each model time step, so that:

$\frac{\partial T}{\partial t}=S+\mathcal{H}$

where $S$ is the original model forecast temperature tendency. In these experiments, as before, the model is run from the beginning of May for four months, but the heating is only applied from the 1st July onwards. Further details about the definition of the heating term, $\mathcal{H}$, can be found in the "Appendix".

The horizontal structure of the heating which is applied is given by a Gaussian function which is set to zero outside a certain region. The imposed heating has a vertical structure similar to a "typical" tropical convective heating profile, such as those shown in Figure 3 of Schumacher et al. (2004) or Figure 6 of Li et al. (2009). It increases fairly steadily to a peak at around $400 \mathrm{hPa}$, before dropping away sharply near the tropopause. Figure 2 shows an example heating profile as used in our experiments, for a surface pressure of $1012 \mathrm{hPa}$. As the heating is applied on model levels, the actual heating applied is concentrated slightly higher in the atmosphere at lower levels due to the adjustment of the model levels to account for the surface orography. However, the impact of this is only seen in the lower part of the atmosphere, and the heating rate at $400 \mathrm{hPa}$ is almost unchanged.

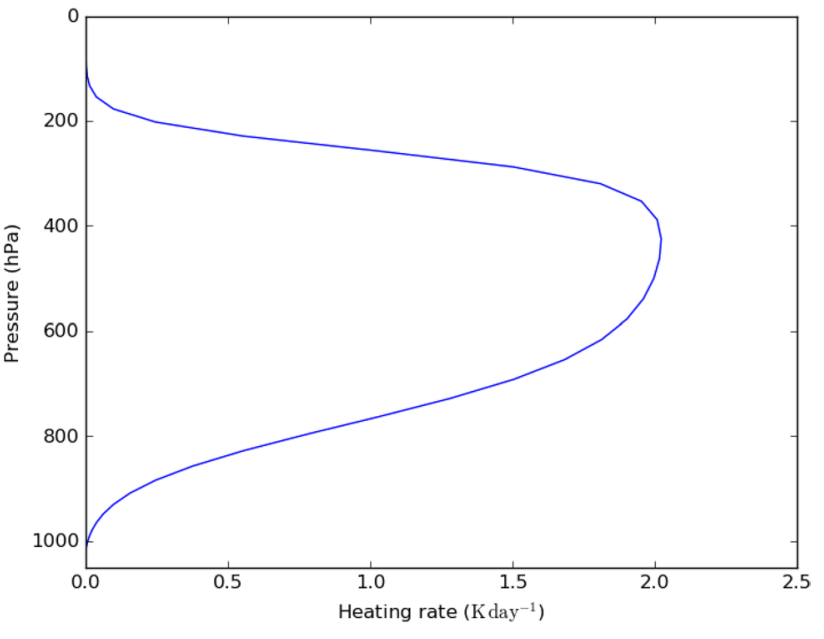

Fig. 2 Example of the vertical heating profile used in the thermal forcing experiments, for a surface pressure of $1012 \mathrm{hPa}$

\subsection{Linear barotropic model}

In Sect. 5, an idealised model is employed to further explore the relationship between ISM heating and the extratropical circulation. The barotropic model used integrates the barotropic vorticity equation on a sphere, following Hoskins and Ambrizzi (1993):

$\left(\frac{\partial}{\partial t}+u_{\psi} \cdot \nabla\right) \zeta=F-\lambda \xi-\mu \nabla^{4} \xi$,

where $u_{\psi}$ is the rotational velocity field, $\zeta$ is the absolute vorticity, $\xi$ is the relative vorticity, $F=\bar{F}+F^{\prime}$ is a constant forcing, $\lambda$ is a linear damping with a timescale of 10 days and $\mu=2.4 \times 10^{16} \mathrm{~m}^{4} \mathrm{~s}^{-1}$ is a diffusion coefficient. Here, $\bar{F}$ is chosen to keep the model stationary in the absence of any additional forcing so that it exactly maintains the basic state:

$\bar{F}=u_{\psi} \cdot \nabla \zeta+\lambda \xi+\mu \nabla^{4} \xi$.

The equation is solved using spectral harmonics with triangular truncation at wavenumber 42 (T42). The model is initialised from the basic state and integrated forward for 50 days. The anomalous forcing, $F^{\prime}$, is scaled to be small so that the response can be interpreted as linear.

\subsection{Verifying data}

Observational atmospheric monthly mean fields come from ERA-Interim reanalysis (Dee et al. 2011) at $80 \mathrm{~km}$ resolution for the period 1981-2014. Observations of precipitation come from the Global Precipitation Climatology Project (GPCP) dataset (Adler et al. 2003). As in Beverley et al. (2019), in order to focus on year-to-year variations, 
we only use the interannual component of the ERA-Interim and GPCP data. We performed Fourier harmonic analysis on the monthly mean data to remove the long term trend and decadal variations with a period of longer than 8.5 years. For both datasets, the period used is 1981-2014, to align with the model hindcast period. A Student's $t$ test was used to assess the statistical significance of calculated correlation values (Wilks 2011).

\subsection{Ensemble sampling}

For the relaxation experiments in Sect. 3, the ECMWF forecast system provides us with multiple realisations in the form of 25 ensemble members. When analysing model output, a common technique is to use the ensemble mean. However, using the ensemble mean reduces the noise and the contribution of the forced variability is increased relative to the total variability. Therefore, to ensure that we do not mistake noise in the observations for forced variability, we need to compare individual ensemble members from the relaxation experiments to the observations. To do this, as in Beverley et al. (2019), we follow the method of Johnson et al. (2016) and construct many time series of monthly averaged variables by randomly selecting an ensemble member from each year and repeating this until we have 2000 sets of time series, of 34 years each. We are then able to compare the single realisation of the observed system to multiple realisations of the simulated system.

\section{Investigating the CGT mechanism using relaxation experiments}

In Beverley et al. (2019) it was shown that regions of reduced geopotential height skill tend to be located in the same regions as the centres of action of the CGT, and that the ECMWF model CGT is generally weaker than in observations. In addition, it was hypothesised by Ding and Wang $(2005,2007)$ that west-central Asia $\left(35^{\circ}-40^{\circ} \mathrm{N}, 60^{\circ}\right.$ $-70^{\circ} \mathrm{E}$, as defined in Ding and Wang (2005) [hereafter the $\mathrm{D} \& \mathrm{~W}$ region]) is an important region in maintaining the CGT. It was also shown in Beverley et al. (2019) (and also in Fig. 3a-c) that errors in geopotential height are present in this region in July and August. Therefore, to investigate whether model errors in the CGT pattern arise as a result of the development of these errors, the first relaxation experiment ("DW_RELAX") relaxed the circulation in a region centred approximately over this area (Table 1). The region chosen is centred slightly to the north of the D\&W region, in order to minimise the impact of the relaxation on the ISM circulation. Analysis of this experiment will determine whether correcting the circulation in this area results in an improved model representation of the CGT.
The weak link between ISM precipitation and west-central Asia in the ECMWF model was also identified by Beverley et al. (2019) as a potential source of the weak model representation of the CGT, due to a weak reinforcement of the wave train by monsoon heating (Ding and Wang 2005, 2007). The second relaxation experiment ("ISM_RELAX") was therefore designed to investigate the impact of errors in the representation of the ISM circulation on the simulation of the CGT and on extratropical skill.

The third relaxation experiment aimed to investigate the impact of the observed atmospheric variability over northwest Europe on the atmospheric evolution elsewhere, as well as the hemispheric impact of any model errors in this region. In the control experiment, an area of reduced model skill first appears over northwest Europe in June, before further areas of reduced skill develop elsewhere in the northern hemisphere. Therefore, to determine whether the errors seen elsewhere (including in the D\&W region) occur as a result of errors propagating from northwest Europe, a third experiment (hereafter "NWEUR_RELAX") was carried out in which a region over northwest Europe was relaxed.

Figure $3 \mathrm{~d}-1$ show the difference in ensemble mean $200 \mathrm{hPa}$ geopotential height skill (defined as the correlation between the model ensemble mean and ERA-Interim) between the control experiment and the three relaxation experiments: DW_RELAX (Fig. 3d-f), ISM_RELAX (Fig. 3g-i) and NWEUR_RELAX (Fig. 3j-1). This is defined such that a positive value indicates that the skill in the relaxation experiment is higher than in the control, and vice versa, and the boxes represent the relaxation regions used. As expected, in DW_RELAX there are large improvements in skill in and around the relaxation region. Away from this region, improvements are largely confined to central and east Asia, downstream of the relaxation region. There is very little change in skill over the North Pacific, North America or Europe. Indeed, in June and July in particular, there is actually a reduction in skill in some parts of Europe. This implies that the errors that appear over west-central Asia in July and August (Fig. 3b, c) are not the dominant cause of reductions in skill elsewhere in the northern hemisphere in these months.

The change in skill in ISM_RELAX is shown in Fig. $3 \mathrm{~g}-\mathrm{i}$. The changes in the relaxation region in this experiment are smaller compared to the other relaxation experiments. This is because the overall skill for $200 \mathrm{hPa}$ geopotential height in the tropics tends to be much better than for the extratropics. The overall pattern of skill change in the extratropics is similar to DW_RELAX. There are some large increases in skill to the north of the relaxation region, including in the $\mathrm{D} \& \mathrm{~W}$ region where there was poor skill in the control experiment. Away from the relaxation region, the patterns of skill change vary from month-to-month. The skill over Europe in June is largely unchanged and is slightly reduced in July. In August, 

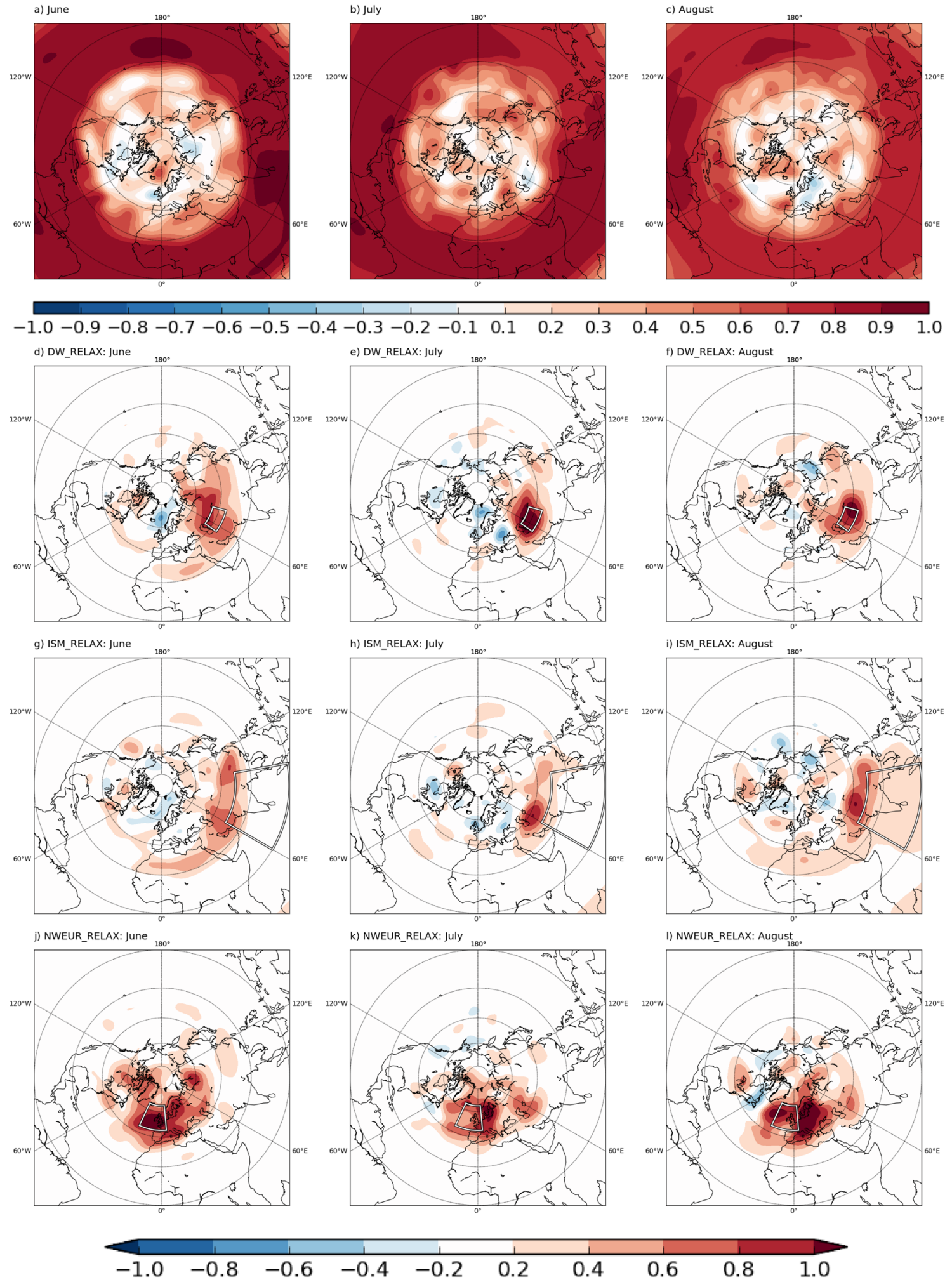

Fig. 3 Skill for $200 \mathrm{hPa}$ geopotential height in the control experiment, as defined as the correlation between ERA-Interim and the 25 member ensemble mean for a June, b July and c August. Relaxation experiment $200 \mathrm{hPa}$ geopotential height correlation skill minus control $200 \mathrm{hPa}$ geopotential height skill for d-f DW_RELAX, g-i
ISM_RELAX and $\mathbf{j}-\mathbf{l}$ NWEUR_RELAX, for June, July and August respectively. A positive value indicates that the skill is increased in the relaxation experiment compared to the control. The boxes indicate the relaxation regions used, which are listed in Table 1 
however, the changes in skill over Europe are largely positive, which may suggest that the ISM is a potential source of skill in this month. There are also large increases in skill over North Africa in June, associated with the monsoondesert mechanism (Rodwell and Hoskins 1996).

When compared to the other two relaxation experiments, it can be seen that relaxing over northwest Europe (Fig. $3 \mathrm{j}-1$ ) results in a more widespread and larger hemispheric improvement in skill. In NWEUR_RELAX, improvements in skill are made across much of Eurasia. In particular, the skill in west-central Asia (in the D\&W region) is improved, suggesting that errors from northwest Europe propagate to this region. However, similar to DW_RELAX, this relaxation has caused a reduction in skill upstream of the relaxation region. In general, the relaxation in NWEUR_RELAX appears to have resulted in a larger improvement in skill across the northern hemisphere than in DW_RELAX and ISM_RELAX, implying that the observed variability over northwest Europe has a larger influence on other parts of the northern hemisphere. This may be associated with the propagation of quasi-stationary Rossby waves from the North Atlantic region along the Asian jet stream (Bollasina and Messori 2018).

A measure of the change in the model representation of the CGT in each of the relaxation experiments compared to the control is shown in the histograms in Fig. 4. For these, the CGT pattern (the correlation between the D\&W Index and $200 \mathrm{hPa}$ geopotential height elsewhere) was calculated for each of the 2000 artificial time series for each experiment, and the pattern correlations for these maps between $30^{\circ}-70^{\circ} \mathrm{N}$ compared to the equivalent from ERA-Interim (Fig. 1) were calculated. These are shown as green bars for the control and blue bars for the three relaxation experiments: DW_RELAX (Fig. 4a), ISM_RELAX (Fig. 4b) and NWEUR_RELAX (Fig. 4c).
Table 1 Regions used for the relaxation experiments

\begin{tabular}{lll}
\hline Experiment name & Region & Domain \\
\hline DW_RELAX & Ding and Wang & $35^{\circ}-45^{\circ} \mathrm{N}, 55^{\circ}-75^{\circ} \mathrm{E}$ \\
ISM_RELAX & Indian monsoon & $0^{\circ}-30^{\circ} \mathrm{N}, 60^{\circ}-100^{\circ} \mathrm{E}$ \\
NWEUR_RELAX & Northwest Europe & $45^{\circ}-65^{\circ} \mathrm{N}, 25^{\circ} \mathrm{W}-5^{\circ} \mathrm{E}$ \\
\hline
\end{tabular}

The boundaries refer to the centre of the tapering band, as described in the "Appendix"

It can be seen that relaxing in west-central Asia has actually resulted in a worsening of the representation of the CGT in the model. The range of pattern correlations in $\mathrm{DW}_{-}$ RELAX is around -0.1 to 0.7 , with a much lower median value of 0.35 compared to 0.59 for the control. Given that in this experiment the D\&W Index has been corrected to ERAInterim, this may suggest that this region is not actually forcing the CGT pattern. This is consistent with the findings of Ding and Wang (2007), who hypothesised that variations in Indian summer monsoon (ISM) precipitation reinforce the west-central Asian high and re-energise the further propagation of the wave train but do not force it directly.

From Fig. $4 \mathrm{~b}$ it can be seen that the representation of the CGT in ISM_RELAX is very similar to the control. The two distributions are very alike, with similar median values $(0.55$ for ISM_RELAX and 0.59 for the control), suggesting that the simulation of the CGT has not been improved by correcting the monsoon circulation. This suggests that either the ISM is not a driver of the CGT in the ECMWF model, or that the pathway that connects the ISM to the CGT has not been improved by the relaxation.

Contrary to DW_RELAX, relaxing over northwest Europe results in an improvement in the representation of the CGT in the model compared to the control, with a median pattern correlation of 0.67 . The distribution is also narrower
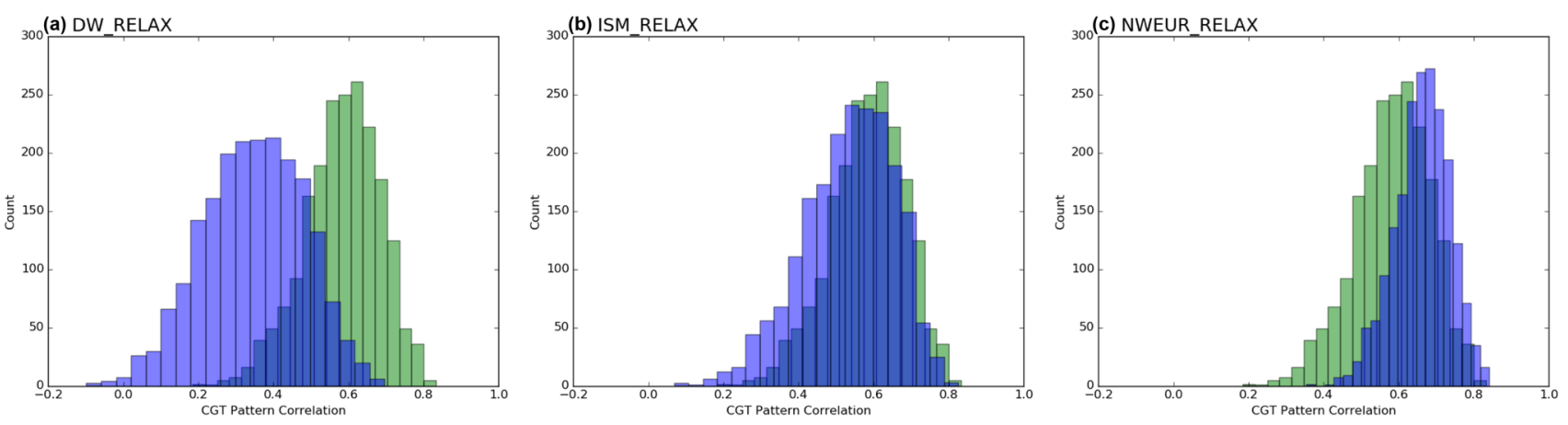

Fig. 4 Histograms of the pattern correlations between ERA-Interim and the ECMWF model CGT correlations for August for the control (green bars) and for a DW_RELAX, b ISM_RELAX and c NWEUR_RELAX (blue bars on each panel), calculated using 2000 time series created from the 25 ensemble members. The pattern correlations were calculated for all longitudes between $30^{\circ}-70^{\circ} \mathrm{N}$. The median value for the control is 0.59 , for DW_RELAX is 0.35 , for ISM_RELAX is 0.55 and for NWEUR_RELAX is 0.67 . In all three cases, the medians of the relaxation experiment distributions are significantly different from the control distribution median value at the $5 \%$ level 
than in the control and DW_RELAX, indicating that more members have a good pattern correlation, and the range of pattern correlations is around 0.35-0.85. The improvements seen in this experiment are largely due to an improvement of the representation of the wave train between northwest Europe and east Asia. Histograms of the pattern correlation for both the eastern and western hemispheres separately have also been produced (not shown), and the median value for the eastern hemisphere $(0.77)$ is much greater than that for the western hemisphere (0.46). This suggests that northwest Europe is more likely to be forcing west-central Asia, rather than the other way round. This wave train was also identified in the composite analysis in Ding and Wang (2007), where a Rossby wave is seen propagating from northwest Europe from eight days before a maximum in the west-central Asian high. This is also in agreement with the results of Di Capua et al. (2020), who used causal effect network analysis to show that a robust link exists on intraseasonal timescales between the North Atlantic Oscillation and their CGT Index (weekly mean $200 \mathrm{hPa}$ geopotential height in the $\mathrm{D} \& \mathrm{~W}$ region).

We now compare the ensemble correlations of the $\mathrm{D} \& \mathrm{~W}$ Index against the other centres of action of the CGT, as well as the relationship between the D\&W Index, ISM precipitation and east Asia (EASIA), for each relaxation experiment and for the control for August (Fig. 5). These correlations were calculated using the 2000 time series created from the 25 ensemble members. The CGT regions used are the same as those defined in Beverley et al. (2019), based on the August observed CGT pattern and are shown as boxes on Fig. 1 and are listed in Table 2.

A common theme between the relaxation experiments for the correlations between the D\&W Index and all other centres of action is that DW_RELAX is poorer than NWEUR RELAX and the control. This is perhaps unexpected, given that in DW_RELAX the D\&W Index is the same (or nearly the same) as in ERA-Interim. What this may imply is that while the $\mathrm{D} \& \mathrm{~W}$ region is an important centre of action, the CGT is not forced directly from this region in the ECMWF model, and the improvements to the representation of the CGT seen in NWEUR_RELAX suggest that errors over northwest Europe are much more important. This is further emphasised when looking at the correlation between the D\&W Index and NWEUR. In NWEUR_RELAX, the relationship between these regions is improved relative to the control, which provides further evidence that the correlation between D\&W and NWEUR in observations is more likely to be acting from Europe to Asia, rather than the other way round. This result was one motivation for the heating experiments presented in Sect. 4.

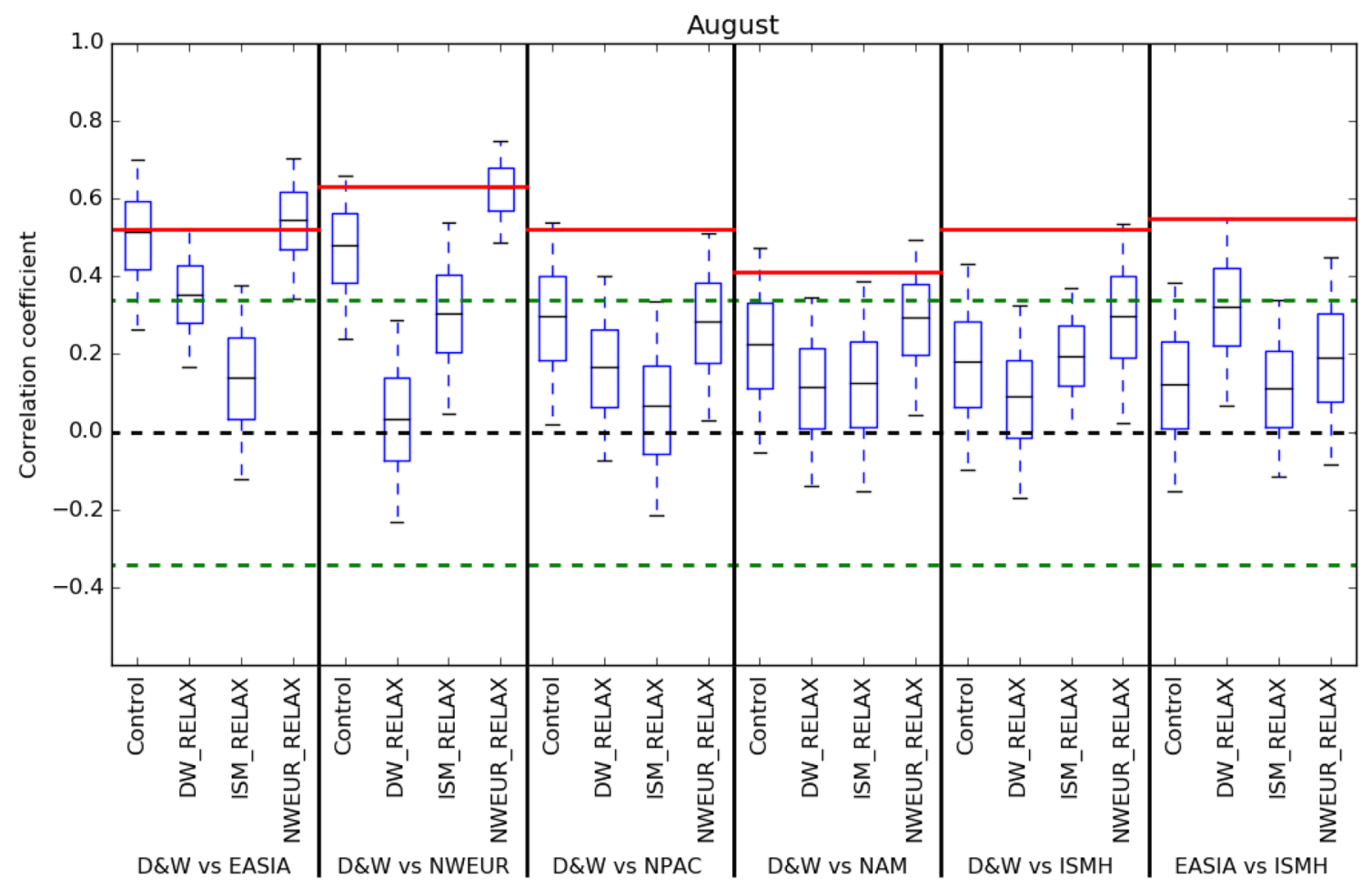

Fig. 5 A comparison of the correlations between different indices for the control and the three relaxation experiments for August, calculated using the 2000 samples. The box plots represent the upper and lower quartiles, and the whiskers extend to the 5th and 95th percen- tiles. The black horizontal line represents the median value and the red horizontal lines the observed correlation coefficient from ERAInterim. 5\% significance levels $( \pm 0.34)$ are indicated by the green dashed lines 
Given the difficulty in understanding how the ISM, EASIA and D\&W region are related to each other, we are not going to focus on the interpretation of these parts of the figure, but we note that relaxing in the D\&W region significantly reduces the correlation between the $\mathrm{D} \& \mathrm{~W}$ region and NWEUR. This might be because when we force the D\&W region the forcing region is relatively close to NWEUR and we may be interfering with the propagation of waves into the relaxation region, which generates errors in the circulation.

It is perhaps surprising that the correlation between the D\&W Index and EASIA region in DW_RELAX is further from ERA-Interim than in the control and NWEUR RELAX, given that the skill of $200 \mathrm{hPa}$ geopotential height in EASIA in DW_RELAX is increased. A possible explanation for this lies in the relationship between these two regions and ISM precipitation. The correlations between an Indian summer monsoon heating index (ISMH), defined as the precipitation averaged between $20^{\circ}-27.5^{\circ} \mathrm{N}, 70^{\circ}$ $-85^{\circ} \mathrm{E}$, and the D\&W Index in DW RELAX are weaker than in both the control and NWEUR_RELAX, suggesting that the link between these two regions has been partially broken by relaxing in the D\&W region. However, the link between ISMH and the EASIA Index, also shown on Fig. 5, is improved in DW_RELAX compared to the control and NWEUR_RELAX. This means that ISMH is still driving the variations in the EASIA Index in DW_RELAX, which results in an improvement in geopotential height skill in EASIA in this experiment. However, as the D\&W Index explains less of the variance in EASIA, the correlation between the two regions is reduced in DW_RELAX.

It can also be seen that the control and the relaxation experiments have a similar weak representation of the link between the D\&W Index and ISMH, which may partially explain the lack of improvement in the representation of the CGT in these experiments. This provided a motivation for more model experiments, in which the relationship between ISM heating and the extratropical circulation is further explored, results from which can be found in the next section.

\section{Thermal forcing experiments}

As seen in the previous section, the link between ISM heating and the extratropical circulation (the $\mathrm{D} \& \mathrm{~W}$ region) in the ECMWF model is too weak compared to observations. Therefore, in order to test the response of the model to heating in the monsoon region, a set of thermal forcing experiments was carried out. We may not expect the model to respond to the applied heating in the same way as it would in the real world, due to the variety of real-world external factors and the idealised nature of the additional forcing. Nevertheless, these experiments can still be used to provide insight into the relationship between monsoon heating and the extratropical circulation in the model.

In these experiments, a heating in the form of an extra temperature tendency is applied at each model time step (further details in Sect. 2.1.3). As with the relaxation experiments presented in Sect. 3, the model is run from the beginning of May, but the heating is only applied from the 1st July onwards and is then constant until the end of the model run at the end of August. Each experiment has five ensemble members and the model is run for start dates between 1981-2014.

In order to find the most suitable region to apply the heating to, the regression of August global precipitation against the D\&W Index was calculated to determine which regions of tropical precipitation (particularly in the vicinity of the ISM) are most closely associated with variations of the D\&W Index. This is shown in the upper panel of Fig. 6, which shows that the strongest regression is located over northwest India, indicating that precipitation in this region has a close relationship with variations of geopotential height in the $\mathrm{D} \& \mathrm{~W}$ region. This is in agreement with other studies which have shown that ISM precipitation is associated with an anticyclonic anomaly over west-central Asia, which is generated through a Rossby wave response to the diabatic heating (e.g. Wang et al. 2001; Wu and Wang 2002).

We then calculated the correlation between precipitation in a box centred over the area of strong regression seen in Fig. $6 \mathrm{a}\left(20^{\circ}-27.5^{\circ} \mathrm{N}, 70^{\circ}-85^{\circ} \mathrm{E}\right.$, the same region (ISMH) as used in Fig. 5) and $200 \mathrm{hPa}$ geopotential height (Fig. 6b). From this it can be seen that precipitation over northern India is not only associated with variations of the D\&W Index, but also the CGT, with a similar correlation pattern to the observed August CGT pattern (Fig. 1). This suggests that heating in this region is strongly related to the strength of the CGT. Therefore, this region was chosen as the location in which to apply the thermal forcing in the ECMWF model.

In these experiments we look at the impact of applying both a positive and a negative heating over the ISM region. The amount of additional heating was specified to have a peak value which is equivalent to approximately $4 \mathrm{~mm}_{\text {day }}{ }^{-1}$ of extra precipitation in the positive heating experiment, and vice versa in the negative heating experiment. This corresponds approximately to a two standard deviation change in the D\&W Index (Fig. 6a), and equates to a peak thermal forcing of $\pm 2.02 \mathrm{~K} \mathrm{day}^{-1}$.

When calculating the total heating difference in these experiments compared to the control, we have to consider both the heating that is applied directly, and also the diabatic heating associated with precipitation changes. This was calculated using Eqs. 13-15 given in the "Appendix". Using these equations, the heating applied in the positive thermal forcing experiment was calculated to have a peak of around $120 \mathrm{~W} \mathrm{~m}^{-2}$, and the combined effect of this imposed thermal 
Fig. 6 a Regression of GPCP global precipitation $\left(\mathrm{mm} \mathrm{day}^{-1}\right)$ against the D\&W Index (ERAInterim $200 \mathrm{hPa}$ geopotential height, box) for August, per standard deviation of the D\&W Index (32.9 m). b Correlation between GPCP precipitation in northern India $\left(20^{\circ}-27.5^{\circ} \mathrm{N}\right.$, $70^{\circ}-85^{\circ} \mathrm{E}$, box) and ERAInterim $200 \mathrm{hPa}$ geopotential height elsewhere for August. Correlation values of \pm 0.34 are significant at the $5 \%$ level (a)

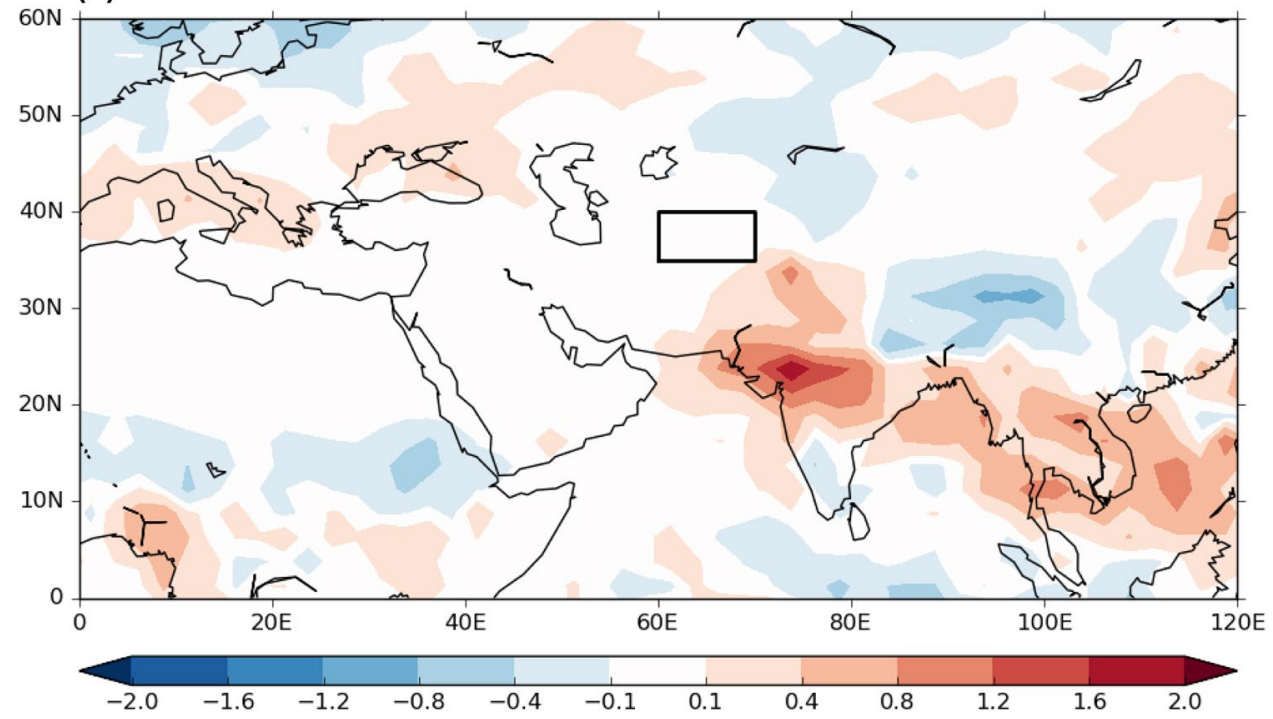

(b)

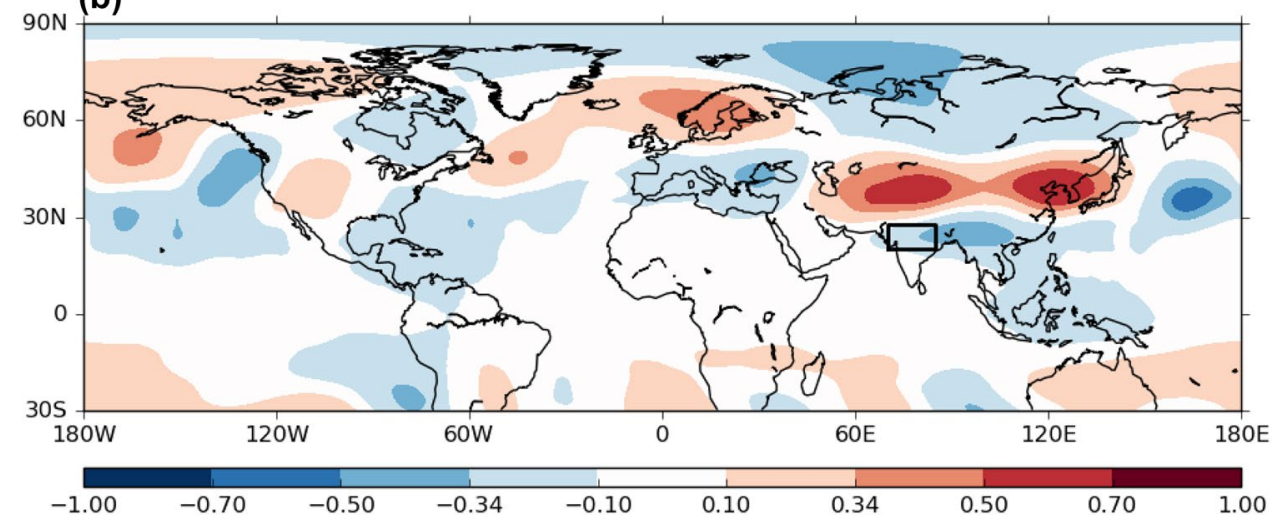

forcing and the resulting precipitation changes on the overall differences in heating in the thermal forcing experiments are shown in Fig. 7. These are with respect to the control experiment.

From Figs. 7a and $7 \mathrm{~b}$ it can be seen that the maximum increase in heating in the positive heating experiment is centred slightly to the west of the region in which the heating was imposed. This is in the region of the largest increases in precipitation (not shown). This precipitation increase is in a similar location to the region of observed positive regression of precipitation against the D\&W Index in Fig. $6 \mathrm{a}$.

Table 2 CGT $200 \mathrm{hPa}$ geopotential height indices

\begin{tabular}{lll}
\hline Index & Abbreviation & Domain \\
\hline Ding and Wang & D\&W & $60^{\circ}-70^{\circ} \mathrm{E}, 35^{\circ}-40^{\circ} \mathrm{N}$ \\
Northwest Europe & NWEUR & $15^{\circ} \mathrm{W}-10^{\circ} \mathrm{E}, 50^{\circ}-70^{\circ} \mathrm{N}$ \\
East Asia & EASIA & $110^{\circ}-140^{\circ} \mathrm{E}, 30^{\circ}-50^{\circ} \mathrm{N}$ \\
North Pacific & NPAC & $180^{\circ}-150^{\circ} \mathrm{W}, 40^{\circ}-60^{\circ} \mathrm{N}$ \\
North America & NAM & $120^{\circ}-90^{\circ} \mathrm{W}, 40^{\circ}-60^{\circ} \mathrm{N}$ \\
\hline
\end{tabular}

The increase is also accompanied by a slight decrease in heating further south, over central parts of India and the Western Ghats, associated with a reduction in precipitation in these areas. From the $850 \mathrm{hPa}$ winds it can be seen that the increase in heating in the positive heating experiment is associated with an extension of the monsoon circulation further north, with stronger winds in this region bringing increased moisture.

The heating differences seen in the negative heating experiment (Fig. 7c, d) are slightly stronger in magnitude than for the positive heating experiment. They are also positioned more towards the centre of the forcing region, associated with a reduction in precipitation over central and northern parts of India. There is also a slight increase in heating over the Arabian Sea, to the west of India.

We now look at the monthly mean response of the model across the northern hemisphere. Figure $8 \mathrm{a}, \mathrm{b}$ show the difference in ensemble mean $200 \mathrm{hPa}$ geopotential height for the positive minus negative heating experiments in July and August. It can be seen that the geopotential height in several of the centres of action of the CGT has been affected by the 

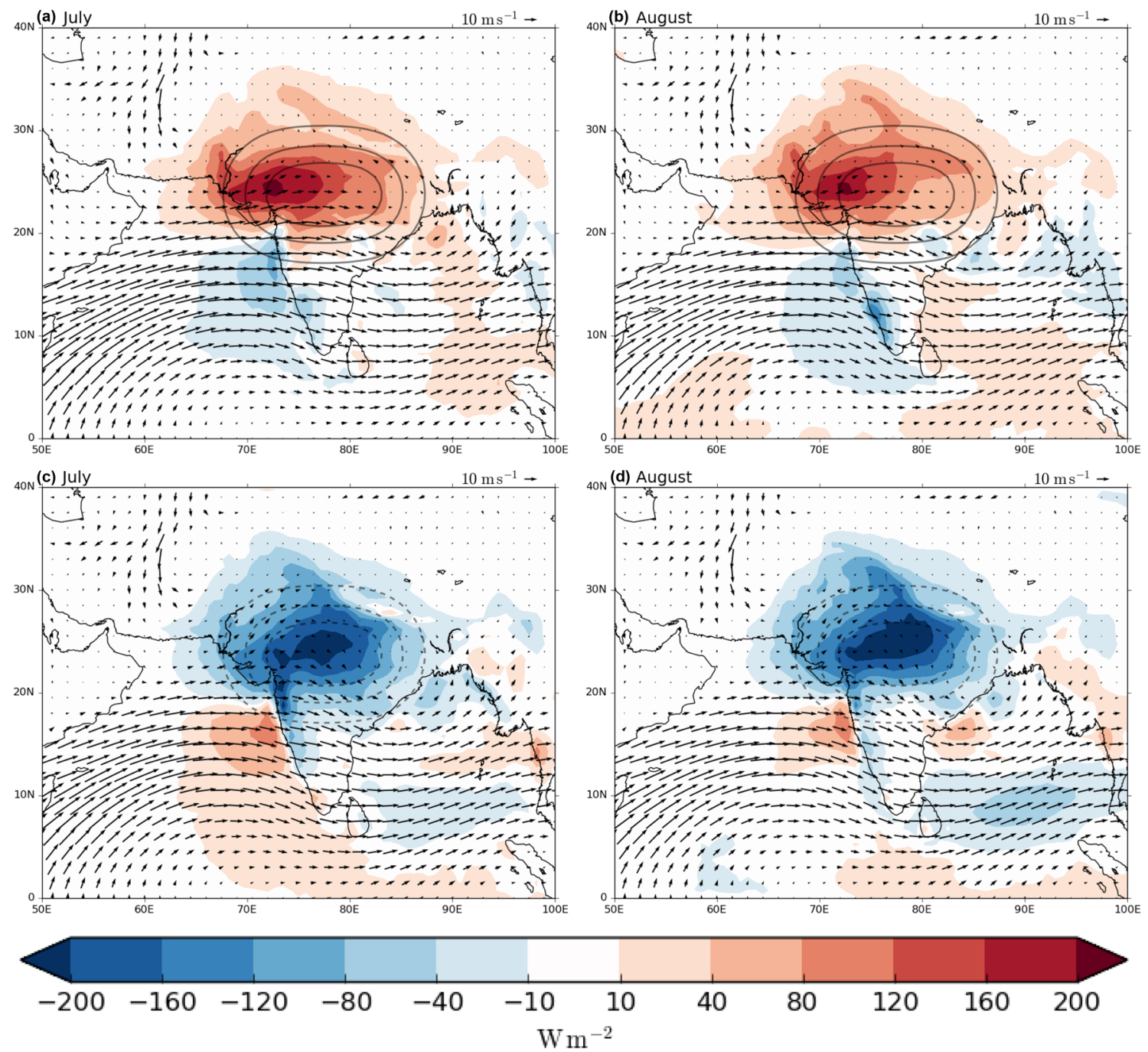

Fig. 7 Ensemble mean latent heating difference $\left(\mathrm{W} \mathrm{m}^{-2}\right)$ for the positive heating experiment minus the control for a July and $\mathbf{b}$ August, and for the negative heating experiment minus the control for $\mathbf{c}$ July

heating. The geopotential height in east Asia and the North Pacific, and also to a lesser extent North America, is up to $50 \mathrm{~m}$ higher in the positive than in the negative heating experiment by August, and the location of the geopotential height change maxima in east Asia and the North Pacific are close to the centres of action of the CGT (white crosses on Fig 8). The differences over east Asia and the North Pacific are approximately equivalent to those associated with a two standard deviation change in the D\&W Index, and the North America anomalies are equivalent to a one standard deviation change (not shown). This suggests that heating associated with the ISM is a driver of the variability in these parts of the northern hemisphere through driving a wave-like response. and $\mathbf{d}$ August, averaged over all years. The black contours indicate the location of the imposed heating-contours at 30,60 and $90 \mathrm{~W} \mathrm{~m}^{-2}$ (dashed contours for negative values). The wind vectors show the absolute $850 \mathrm{hPa}$ wind

However, the response over the North Atlantic and the NWEUR region is very different to the CGT. Over central and northern Europe and the far North Atlantic there are broadly cyclonic anomalies, which are the opposite of what would be expected in the NWEUR region due to the CGT. There is a strong response visible over North Africa and the Mediterranean, as a result of the Rodwell and Hoskins (1996) monsoon-desert mechanism whereby heating associated with the monsoon triggers westward-propagating Rossby waves. The response over North Africa and the Mediterranean is very different to that seen in Fig. 6b. This may suggest that the precipitation in the heating region is a response to forcing from the CGT, rather than a driver of it. This is further supported by the different response in the 
Fig. 8 Ensemble mean $200 \mathrm{hPa}$ geopotential height difference (m) for the positive minus negative heating experiment for a July and b August, averaged over all years. c July and $\mathbf{d}$ August $200 \mathrm{hPa}$ geopotential height difference relative to ERA-Interim standard deviation (difference divided by standard deviation). The location of the observed centres of action of the CGT are marked with white crosses (a) Z200 difference - July

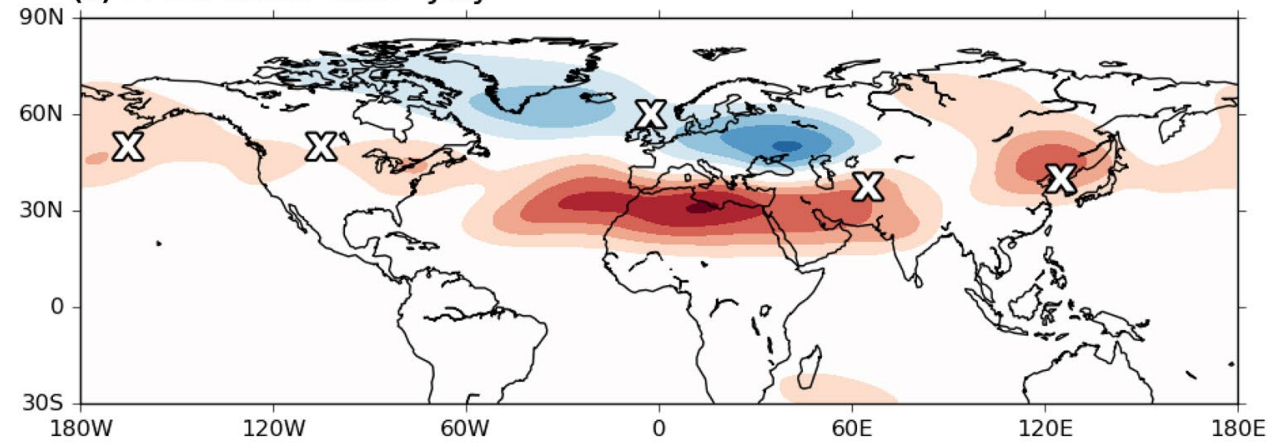

(b) Z200 difference - August

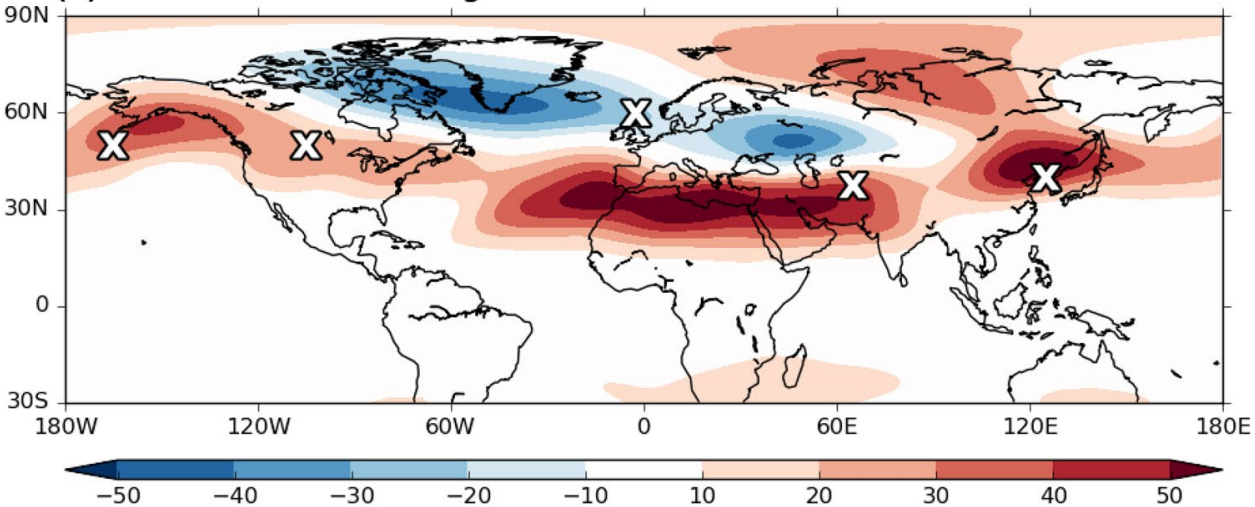

(c) Z200 difference relative to ERA-I standard deviation - July

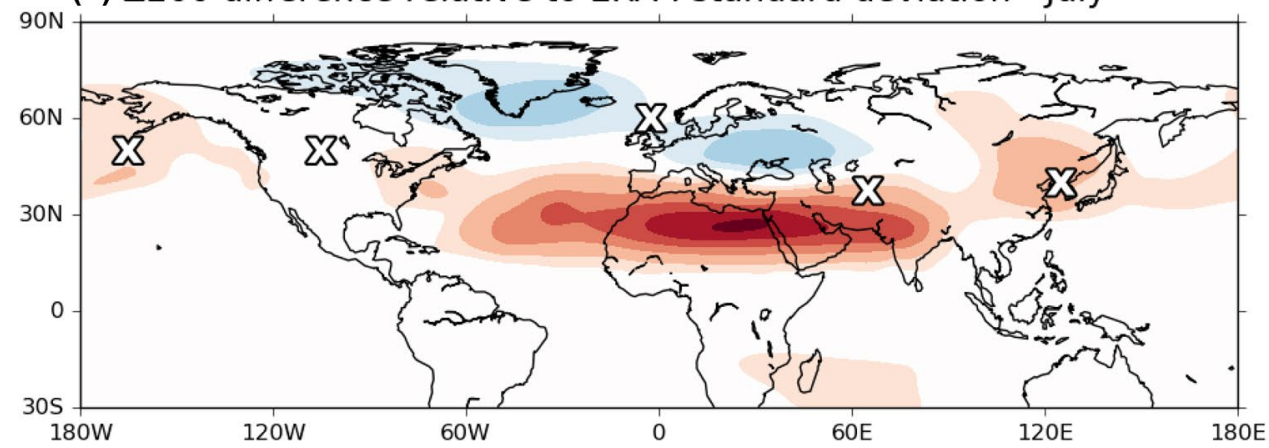

(d) Z200 difference relative to ERA-I standard deviation - August

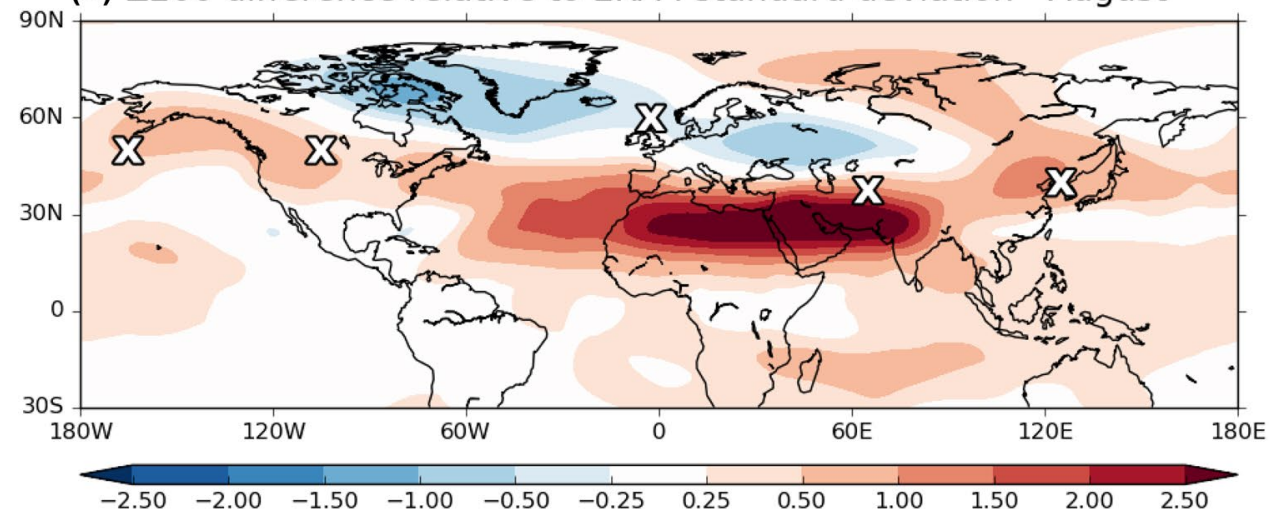



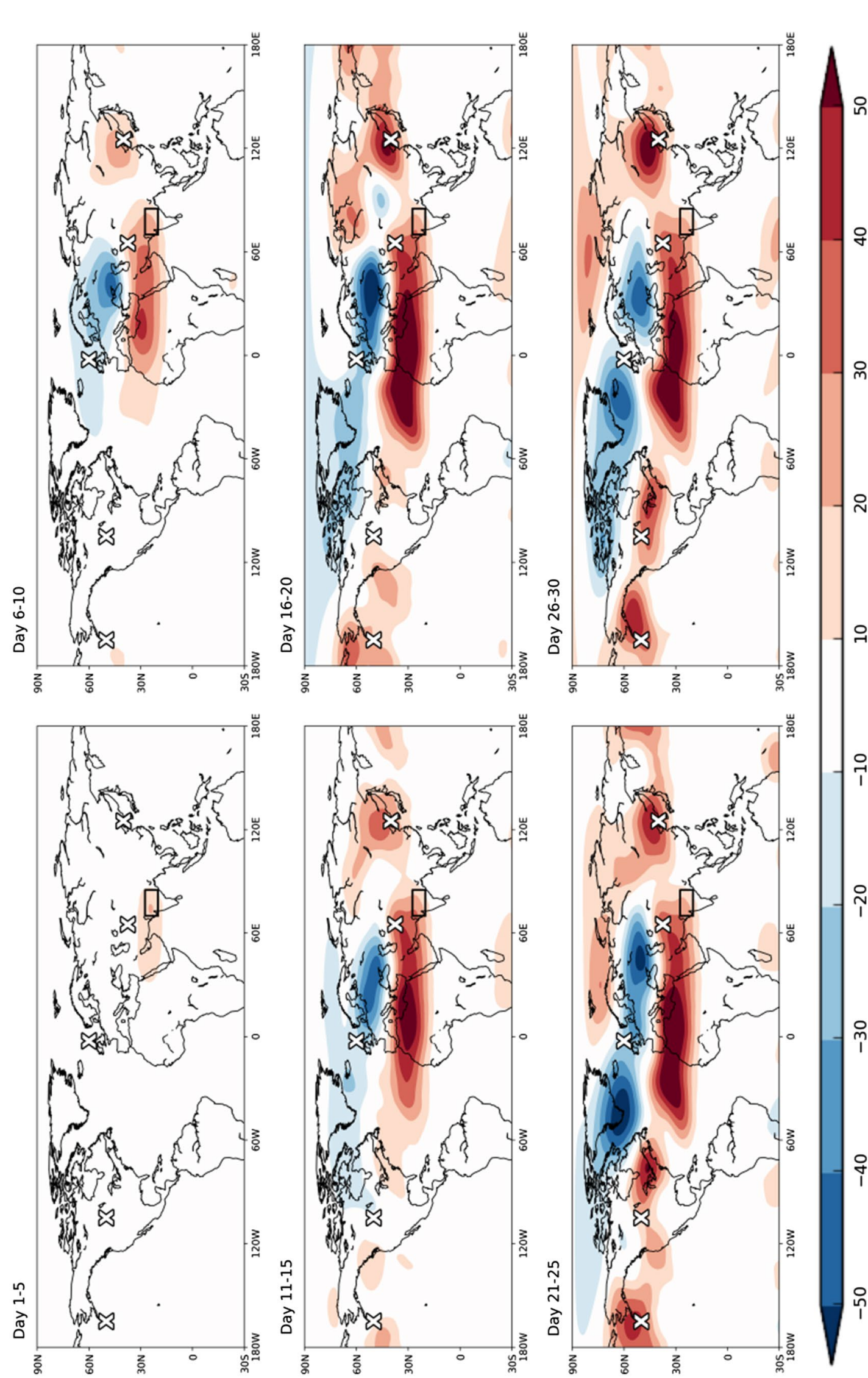

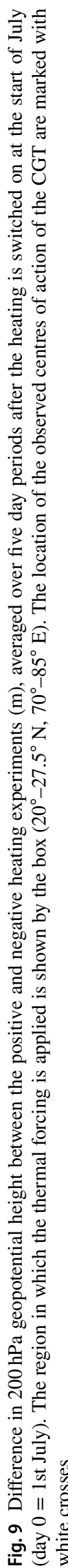


D\&W region when compared to the CGT, with no positive anomalies located in this region.

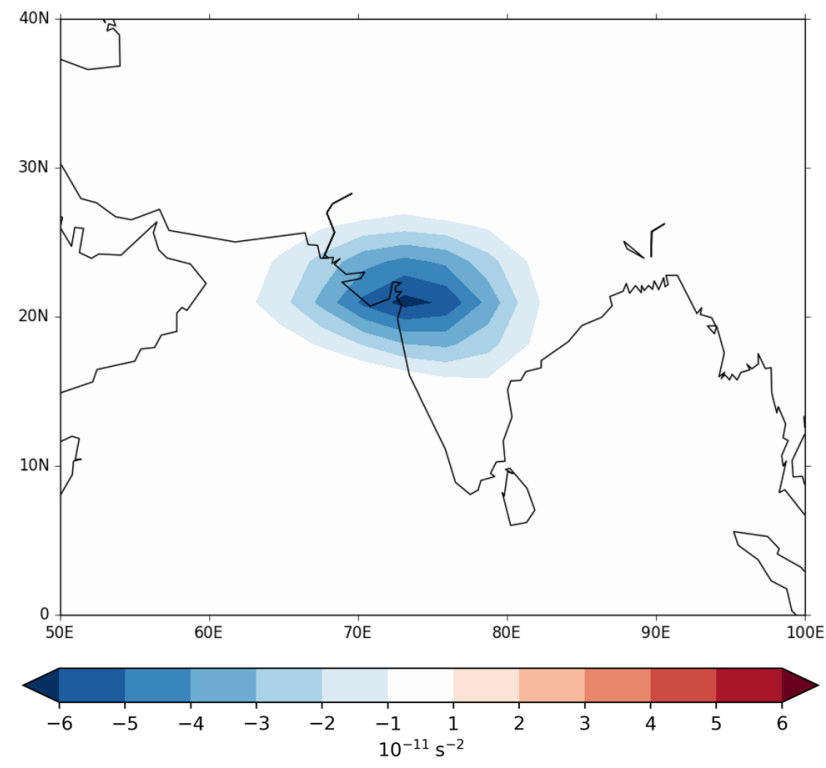

Fig. 10 RWS forcing used in the barotropic model experiments, calculated using the difference in divergence between the positive heating experiment and the control (BT_ISMN)
The difference in $200 \mathrm{hPa}$ geopotential height relative to the standard deviation of ERA-Interim is shown in Fig. 8c, $\mathrm{d}$. The differences seen associated with the monsoon-desert mechanism are equivalent to up to 3 times the observed standard deviation, indicating that these differences represent a large change relative to usual variability. The difference over east Asia is between 1 and 1.5 observed standard deviations, although the changes over the North Pacific, North America and Europe are equivalent to less than 1 standard deviation.

To examine how the response to the thermal forcing develops over time, Fig. 9 shows the difference in $200 \mathrm{hPa}$ geopotential height between the two experiments averaged over five day periods after the heating is applied. In this figure, Day 0 is the first day after the heating is turned on (1st July). In the first 5 days, the only anomalies that are visible occur as part of the monsoon-desert mechanism, with anticyclonic anomalies appearing in and to the west of the heating region, and a weak cyclonic anomaly to the north of this, which grows in magnitude by Days $6-10$. By this point, anticyclonic anomalies have also appeared over east Asia and have begun to grow over the North Pacific as an eastward-propagating Rossby wave response develops. The westward-propagating anomalies have also extended across North Africa to the North Atlantic, and by Days

Day 4
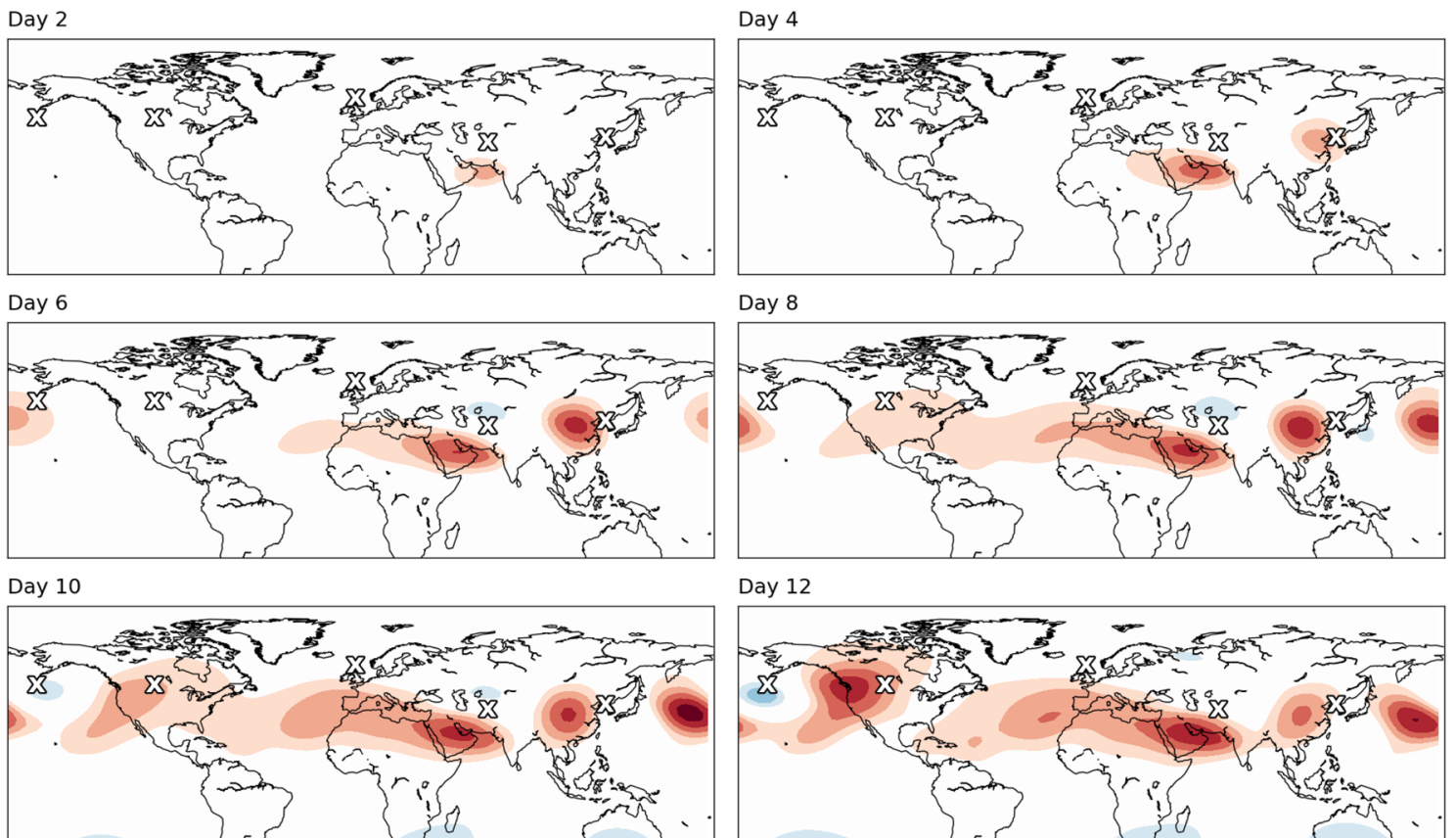

Day 8

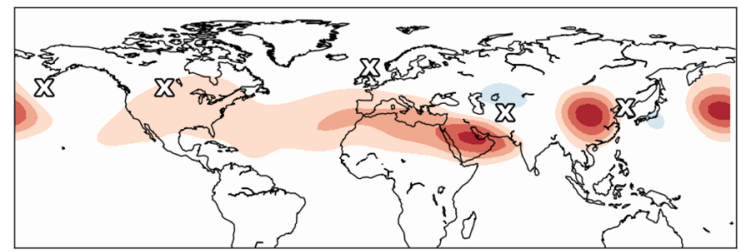

Day 12

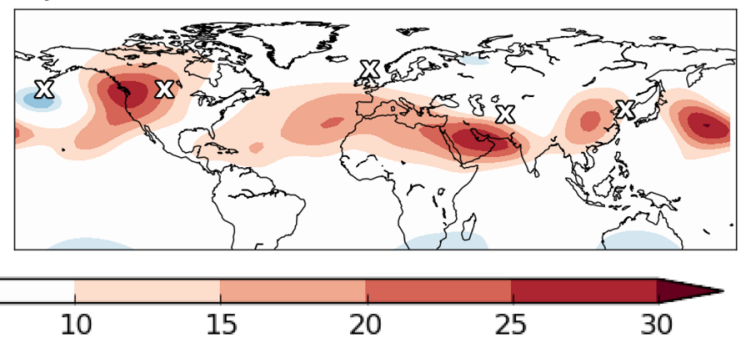

$\psi\left(10^{5} \mathrm{~m}^{2} \mathrm{~s}^{-1}\right)$
Fig. $11200 \mathrm{hPa}$ streamfunction anomaly every other day up to Day 12 in the barotropic model experiment which is forced over India using the RWS calculated from the difference in divergence between the positive thermal forcing experiment and the control (BT_ISMN). The forcing used is shown in Fig. 10. The location of the observed centres of action of the CGT are marked with white crosses 

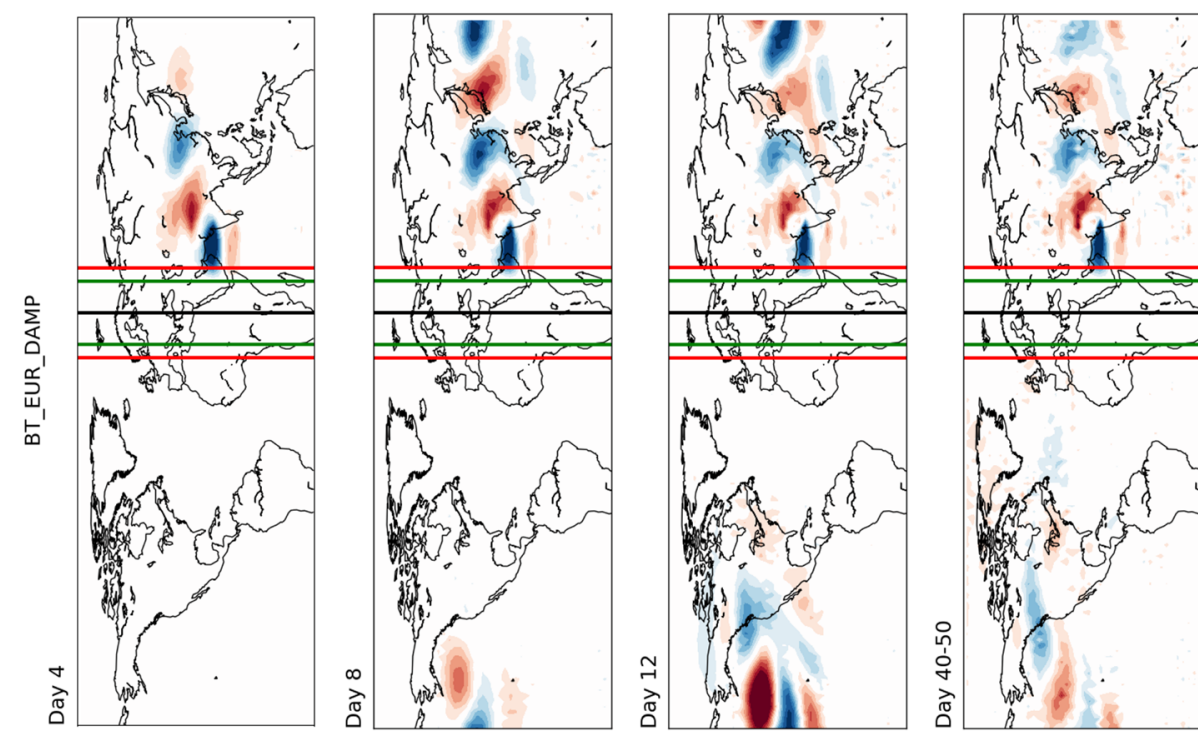

$\frac{1}{8}$
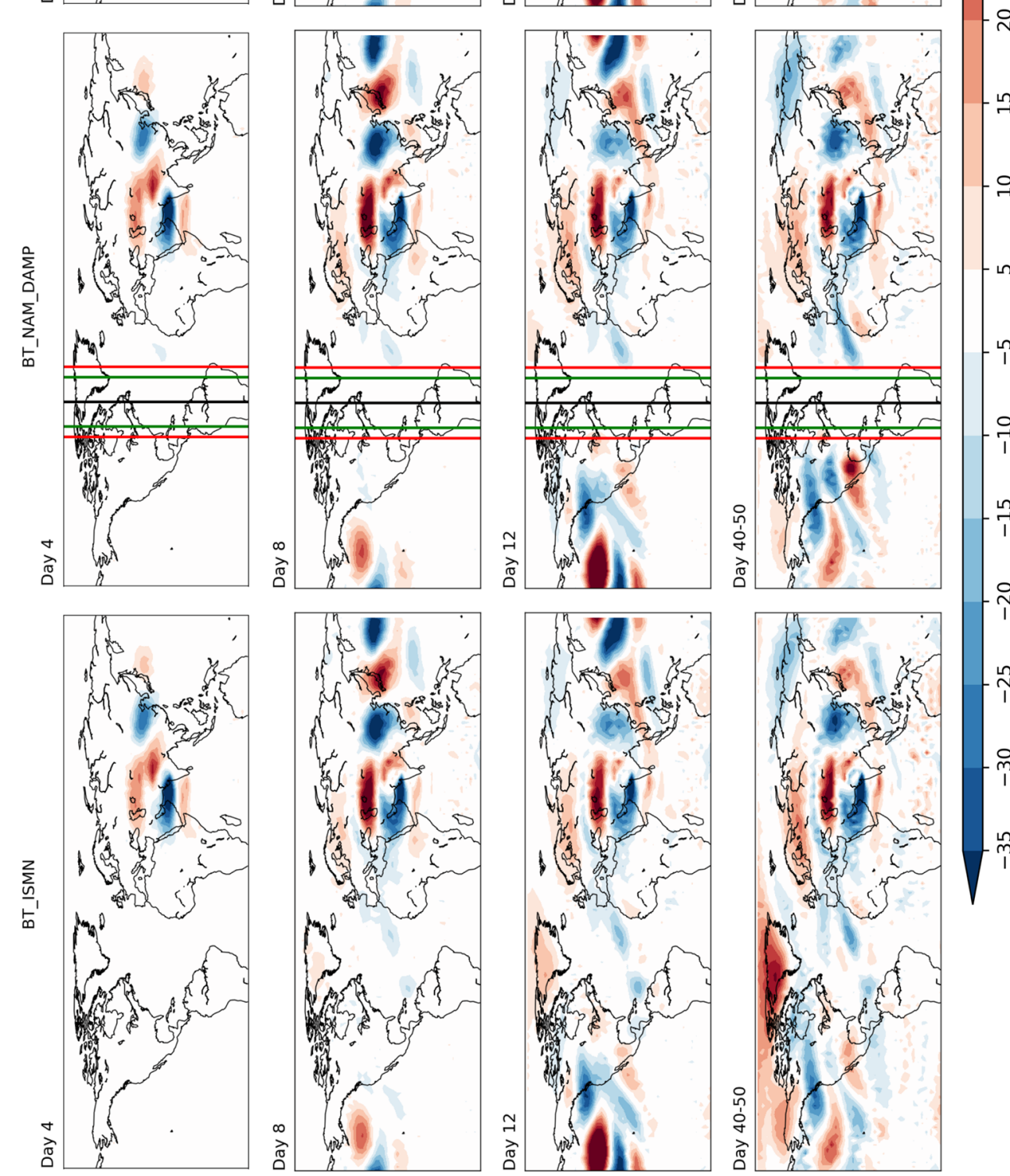

บิ

远.

프으

$\stackrel{0}{0}$

焉

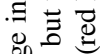

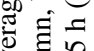

空

害 记

을

의

ข ป

可

3 的

Zิ่อ

空苇

늘

二

宔

进

官

运

in $\sum$

ì

这察

궁

总造

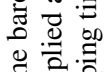

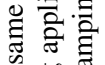

을

클 홍

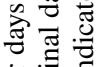

竞:

중

ป 의

줄

宅 音

突官

言

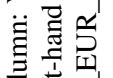

穵步

플 띠

ज्ञ

ब्ञ

$\simeq \stackrel{\mathscr{V}}{0}$

站高 

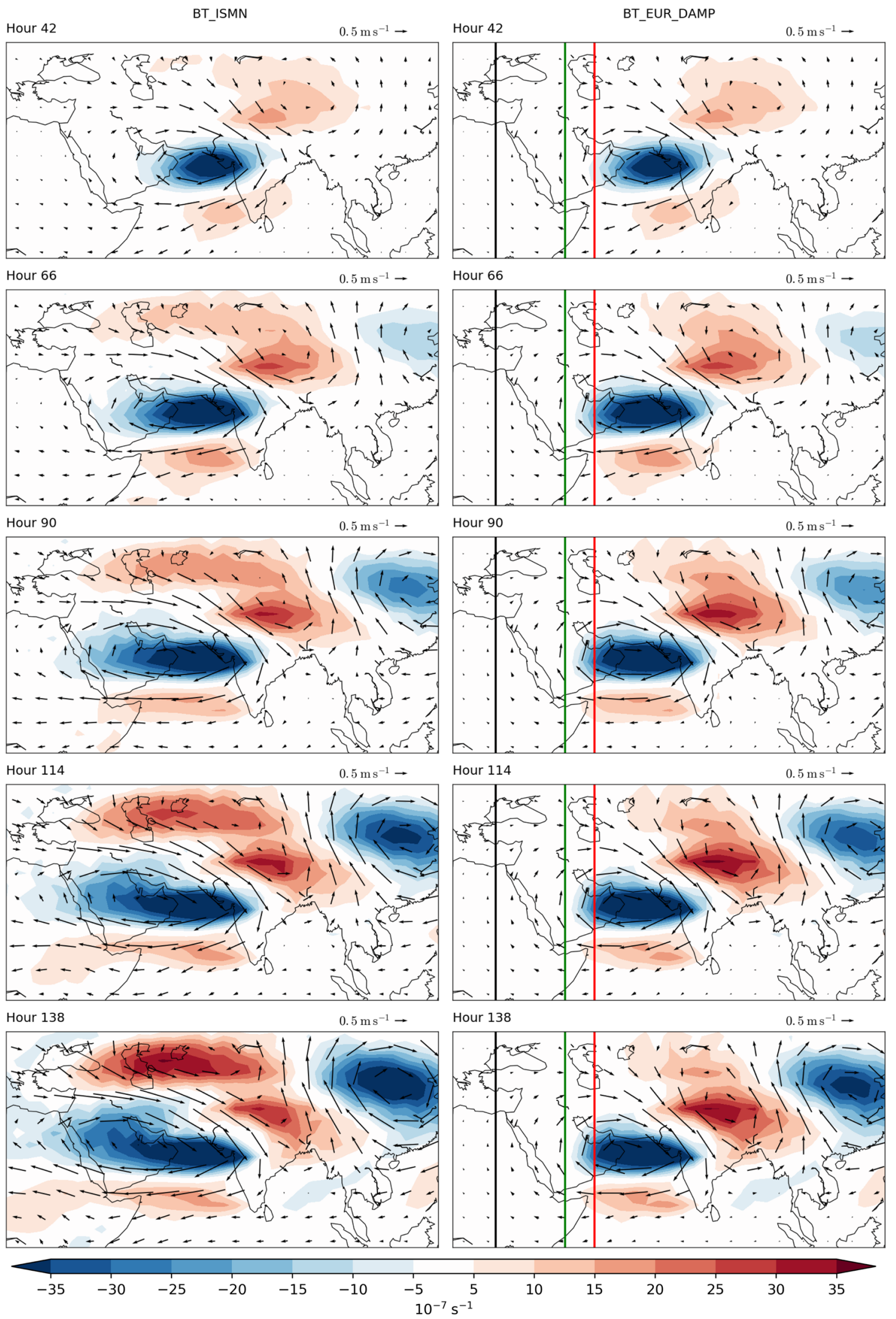
4Fig. 13 Left-hand column: Vorticity (coloured contours) and wind (vectors) anomalies in BT_ISMN at hour 42, 66, 90, 114 and 138. Right-hand column: Same as the left-hand column, but for BT_EUR_ DAMP. The vertical lines indicate the damping timescale at different longitudes: $15 \mathrm{~min}$ (black line) $2.5 \mathrm{~h}$ (green line) and $25 \mathrm{~h}$ (red line)

16-20 these anomalies have reached their peak magnitude, from which point they remain almost constant. The east Asia anomalies also reach their peak magnitude by Days 16-20, while the North Pacific and North America nodes continue to grow until Days 21-25. The North America anomalies seem to arise in part from the interference between the westward- and eastward-propagating waves. From Days 21-25 onwards, the response is largely stationary over the Mediterranean, east Asia and the North Pacific, but the node over North America is a little more transient, shifting in location between west and east North America.

The European response is set up within 10-15 days of the heating being applied, and it is clear that the main differences seen over Europe occur not as a result of the propagation of Rossby waves eastwards from the heating region but as a consequence of the westward-propagating Rossby waves. Throughout the period shown in Fig. 9 the differences in the NWEUR CGT centre of action are cyclonic, unlike the anticyclonic differences seen elsewhere in the hemisphere, and they appear to be the opposite of what would be expected for a CGT-like response. To further understand the development of the response to the heating, we now perform experiments in a linear barotropic model, which are presented in the next section.

\section{Barotropic model experiments}

We now use the barotropic model described in Sect. 2.2. The anomalous forcing, $F^{\prime}$, is taken to be the Rossby wave source (RWS) calculated using the difference in divergence between the positive thermal forcing experiment and the control (a negative RWS, "BT_ISMN"). The vorticity is taken from the ECMWF model control experiment, and so the RWS equation becomes:

$R W S=-\zeta_{\text {control }} D_{\exp }-\mathrm{v}_{\chi \exp } \cdot \nabla \zeta_{\text {control }}$,

where $\zeta$ is the absolute vorticity, $D$ is the divergence and $\mathrm{v}_{\chi}$ is the divergent part of the wind field. The terms with subscript "control" are taken from the ECMWF control experiment and with "exp" are calculated from the difference in divergence between the positive thermal forcing experiment and the control. The calculated RWS forcing used in this experiment is shown in Fig. 10. The basic state used is the
July-August average $200 \mathrm{hPa}$ relative vorticity field from the ECMWF model control experiment.

Figure 11 shows the evolution of the streamfunction anomalies in this experiment every other day up to Day 12. There is clear eastward propagation of Rossby waves from the forcing region across the North Pacific to North America. Associated with these are centres of action (positive, anticyclonic streamfunction anomalies) in east Asia and the North Pacific, although these are shifted westwards relative to the location of the centres of action of the CGT (the white crosses on Fig. 11). There is also a westward-propagating signal which influences the circulation over the Mediterranean and North Africa, which is consistent with that seen in the thermal forcing experiments. The wave signal becomes less clear over North America as it interacts with the westward-propagating waves, and this interaction means that there is no clear centre of action over North America. The propagation of the waves in this experiment is highly consistent with the results from the thermal forcing experiments shown earlier, albeit with the slight westward shift of the anomalies. The evolution of the signal over Europe in these experiments is also similar to the thermal forcing experiments, whereby the circulation anomalies in this region appear to be influenced by a westward- or northwestwardpropagating signal from the forcing region, rather than from the west via a CGT-like response.

To explore the development of the European response in greater detail, we now follow the method of Shaman and Tziperman (2007) and O'Reilly et al. (2018) and add sponge layers at specific longitudes which damp the nearby vorticity anomalies and prevent the zonal propagation of Rossby waves. This allows us to determine the contribution of the westward- and eastward-propagating waves to the development of vorticity anomalies in the northern hemisphere.

The sponge layers, which have a Gaussian longitudinal profile, were implemented through the addition of a term on the right-hand side of the vorticity equation (Eq. 4) of the form:

$-r_{D}(\zeta-\bar{\zeta})$

where

$r_{D}=\exp \left(-2\left(\frac{\lambda-\lambda_{\mathrm{DAMP}}}{15}\right)^{2}\right)$.

Here, $\lambda$ is the longitude and $\lambda_{\text {DAMP }}$ is the longitude at which the damping is centred. The first of these sponge layers was added at $60^{\circ} \mathrm{W}$, from pole-to-pole, and the evolution of the vorticity anomalies in this experiment ("BT_NAM_DAMP”) and the equivalent experiment with no damping (BT_ISMN) are shown in Fig. 12 (left and centre columns). It can be seen that the midlatitude response in these two experiments 
develops in a very similar manner, with an obvious wave train propagating eastwards from the forcing region. The westward propagating signals in these two experiments are also extremely similar, such that in the day 40-50 average the anomalies over Europe are almost identical in the two experiments, providing further evidence that the response in this region to forcing from the ISM occurs via westwardpropagating Rossby waves. These results are similar to those of Shaman (2014), who found that the response over Europe to ENSO-related forcing in late summer (JAS) is dominated by a westward-propagating signal, and also the results from the tropical Pacific forcings of O'Reilly et al. (2018), in which a similar signal was observed.

Stephan et al. (2019) proposed a positive feedback loop between ascent over India and descent over the Mediterranean, whereby the ISM-induced Mediterranean descent (which occurs through the monsoon-desert mechanism) can subsequently induce rising motion over South Asia following the propagation of anomalies along the Asian jet, associated with the Silk Road Pattern (Lu et al. 2002; Enomoto et al. 2003). To investigate this mechanism, and its relationship with the development of downstream anomalies over North America, a further experiment was carried out with the sponge layer centred at $30^{\circ} \mathrm{E}$ (“BT_EUR_DAMP”). The vorticity anomalies in this experiment are shown in the righthand column of Fig. 12. Comparing the damped experiment to the undamped experiment, the effect of preventing the westward-propagating waves can be clearly seen. Early in the simulation, the eastward-propagating response is similar in both experiments. However, by Day 40-50, the anomalies in BT_EUR_DAMP over the North Pacific and North America are weaker. This suggests that the propagation of waves between Asia and North America, associated with the "Tokyo-Chicago Express" wave train (Lau and Weng 2002; Lau et al. 2004), does occur when the westward-propagating waves are damped, but they are much weaker. This agrees with the hypothesis of Stephan et al. (2019), and implies that the westward-moving Rossby wave response is crucial in amplifying the subsequent eastward propagation of the wave train between Asia and North America. This is also similar to the results of Di Capua et al. (2020), who showed that rainfall in the monsoon trough region does exert a forcing on the CGT (the D\&W region), although this link is weaker than the reverse. The interference between the eastwardand westward-propagating signals over North America may also be important in the development of the North America anomalies, and this agrees with results from the ECMWF thermal forcing experiments.

To further understand this mechanism, we now examine the response near the forcing region in BT_EUR_DAMP in greater detail. Figure 13 shows the vorticity and wind anomalies in BT_ISMN and BT_EUR_DAMP, focussing this time near the forcing region in the first few days of the simulation.
As in Fig. 12, the vorticity and wind anomalies early in the simulation are very similar in the two experiments, with little difference between them at hour 42 . However, from this point on, the anomalies in the two experiments begin to differ. In BT_ISMN (left-hand column of Fig. 13) a strong westward-propagating negative vorticity anomaly is able to develop, and this extends across the northern Arabian Sea and the Middle East by hour 138. In BT_EUR_DAMP, these anomalies are prevented from extending much beyond the eastern parts of the Middle East. As a consequence of this, there is a much greater southerly component to the anomalous wind over the Middle East in the damped experiment, and these southerly wind anomalies will advect low vorticity air to higher latitudes. This prevents the development of the area of positive vorticity anomalies near the Caspian Sea that can be seen in the experiment with no damping, which are hypothesised to be important in the subsequent downstream reinforcement of the wave train through the propagation of these anomalies along the Asian jet stream. When no damping is applied, the negative vorticity anomalies associated with the westward-moving response effectively cut off the anomalous southerlies, allowing the positive vorticity anomalies to develop to the north.

\section{Conclusions}

The circumglobal teleconnection (CGT) is a wavenumber-5 wave train with centres of action over west-central Asia, east Asia, the North Pacific, North America and northwest Europe (Fig. 1). Here, we further examined the representation of the CGT in the ECMWF seasonal forecast model, and also the mechanisms linking the Indian summer monsoon (ISM) and the extratropical circulation. This work was performed with the aim of answering the following questions, as posed in Sect. 1:

\section{- What impact does heating associated with the ISM have on the extratropical circulation, and what is its role in forcing the CGT?}

To explore the impact of ISM heating on the northern hemisphere circulation, two thermal forcing experiments in the ECMWF model were carried out. In these, forcing over the ISM region leads to a strong signal over North Africa, associated with the monsoon-desert mechanism (Rodwell and Hoskins 1996), and also a clear eastwardpropagating wave train response, with areas of increased geopotential height over east Asia, the North Pacific and North America associated with increased monsoon heating, with maxima in similar locations to the centres of action of the CGT in these regions. However, the wave train does not project eastwards into the North Atlantic/ Europe, suggesting that the CGT centre of action in this 
region is not forced directly by the ISM. The anomalies over northern Europe are cyclonic, and appear to result from a westward- and northwestward-propagating signal from the ISM region. These anomalies develop before the eastward-propagating Rossby waves have travelled around the hemisphere.

Barotropic model experiments, forced using a Rossby wave source applied over India, show a response which is very similar to that from the full ECMWF model, although with a slight westward shift of the circulation anomalies, which supports the idea that the mechanism is through Rossby wave propagation from the heating region. These experiments have similar eastward- and westward-propagating signals, and the development of the response over North America through the interference of these is also very similar in the thermal forcing and barotropic model experiments.

- How does the Indian monsoon influence the circulation over Europe?

Following Shaman and Tziperman (2007) and O'Reilly et al. (2018), further barotropic model experiments were carried out in which sponge layers were added at certain longitudes to prevent the zonal propagation of Rossby waves through the layer. When a sponge layer was added at $60^{\circ} \mathrm{W}$, the $40-50$ day average vorticity anomalies throughout the midlatitudes were very similar to the equivalent experiment with no damping. In particular, the response over Europe was very similar, which further indicates that the influence of the ISM on Europe occurs largely as a result of westward-propagating Rossby waves from the monsoon region, rather than an eastward-moving wave train.

Stephan et al. (2019) hypothesised that the Silk Road Pattern (SRP) wave train relies on a positive feedback loop between ascent over India and descent over the Mediterranean. In order to further investigate this mechanism, and its importance in the propagation of the Rossby wave train across the Pacific to North America, another experiment was carried out in which the damping was applied at $30^{\circ} \mathrm{E}$. In this experiment, the vorticity anomalies over the eastern North Pacific and North America have a weaker magnitude by Day 40-50 when compared to the experiment without damping. When examining the response near the forcing region in closer detail, it was found that in the damped experiment there is a much greater southerly component to the anomalous wind over the Middle East. This acts to advect low vorticity air to higher latitudes and suppresses the positive vorticity anomaly that develops near the Caspian Sea in the undamped experiment, which is important in the subsequent downstream reinforcement of the wave train. This reinforcement occurs through the mechanism proposed by Stephan et al. (2019) as follows. Ascent over India

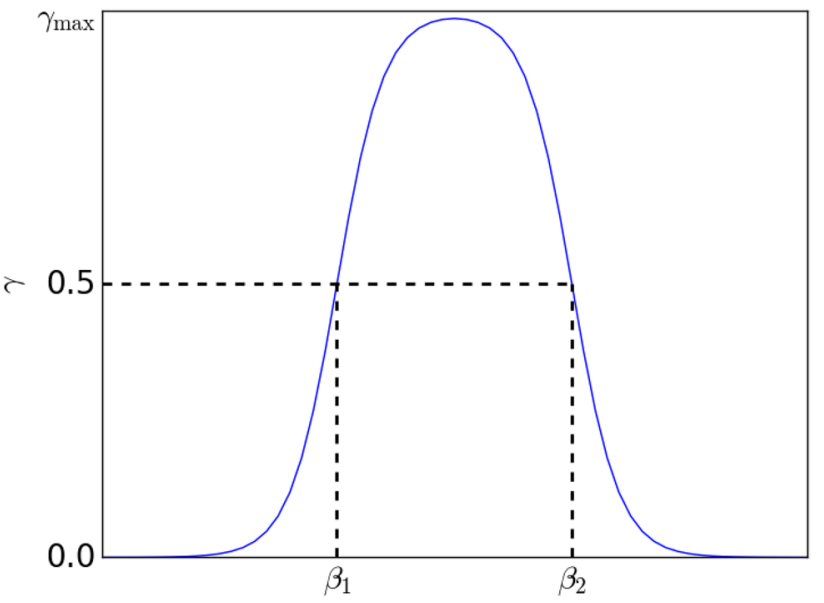

Fig. 14 An example of one component of the weighting function, $\gamma$, used to taper the transition from relaxed to non-relaxed regions. $\beta_{1}$ and $\beta_{2}$ are the relaxation region boundaries and the value of $\gamma_{\max }$ depends on the size of the relaxation region used

leads to westward-propagating Rossby waves, associated with the Rodwell and Hoskins (1996) monsoondesert mechanism. This in turn results in descent over the eastern Mediterranean, which subsequently induces downstream anomalies which propagate along the Asian jet stream and reinforce ISM precipitation in a positive feedback loop. By adding the damping at $30^{\circ} \mathrm{E}$, we have cut off part of this feedback loop and the downstream wave train is weaker as a result. This suggests that the westward-propagating Rossby wave response to forcing in the ISM region is crucial in the downstream propagation of the SRP/Tokyo-Chicago Express wave train.

- What are the main reasons for lack of skill in the representation of the CGT in the ECMWF model?

Beverley et al. (2019) showed that ECMWF model errors in geopotential height develop in several of the centres of action of the CGT. Relaxation experiments were carried out to explore different aspects of the CGT mechanism and the relationship between these model errors and the weak representation of the CGT in the ECMWF model. Three experiments were performed, in which the circulation was corrected towards ERAInterim in each of west-central Asia, the ISM region and northwest Europe in turn.

Of these experiments, the largest improvements in skill in the northern hemisphere were seen in the northwest Europe relaxation, suggesting that this region is a more important source of poor skill in the northern hemisphere than the ISM or west-central Asia. The representation of the CGT was also improved in the northwest Europe relaxation, but was unchanged or slightly worsened in the ISM and west-central Asia relaxations. However, the link between monsoon precipitation and the extratropical 
circulation was found to be weaker than observed in the control and all relaxation experiments. This may mean that the CGT wave train is not being correctly reinforced by monsoon precipitation, which may impact on its subsequent downstream propagation and limit any potential improvements in its representation in the ECMWF model. Alternatively, Ding et al. (2011) suggested that one explanation of the structure of the CGT may lie in the barotropic instability of the midlatitude basic state, and therefore tropical sources may not be responsible for the excitation of the CGT. They found that this barotropic instability is significant over the North Atlantic region, in approximately the same location as the relaxation region in NWEUR_RELAX, which may explain the improvements seen in this experiment.

Through the utilisation of a range of different types of model experiment, including relaxation and thermal forcing experiments in the ECMWF model and simple damped barotropic model experiments, we have shown that ISM heating drives both an eastward- and westward-propagating response, with the westward response important in reinforcing the wave train between Asia and North America. A potential future avenue of research may lie in the nature of thermal forcing that is applied-in our experiments, the forcing is constant from the start of July onwards, but it would be interesting to repeat the experiments with a shorter forcing (e.g. heating for 1 week) or with pulses of heating, as in the experiments of Branstator (2014). Although not part of a CGT-like wave train, the northern European circulation is still influenced by variations in ISM heating and further investigation is required to determine if this mechanism can be used as a potential source of skill for summer weather in this region.

\section{Appendix}

\section{Relaxation technique}

When performing relaxation experiments, in order to avoid adverse effects at the boundaries of the relaxation region, the strength of the relaxation is smoothed using a weighting function $\gamma(\phi, \lambda)$, which governs the transition from relaxed to non-relaxed regions. Here $\phi$ is the latitude and $\lambda$ the longitude of the relaxation region boundaries. For the experiments in Section 3:

$\gamma(\phi, \lambda)=f\left(\phi, \phi_{1}, \phi_{2}\right) f\left(\lambda, \lambda_{1}, \lambda_{2}\right)$,

where

$f\left(\beta, \beta_{1}, \beta_{2}\right)=\left(\frac{1}{1+e^{\delta\left(\beta-\beta_{1}\right)}}\right)\left(1-\frac{1}{1+e^{\delta\left(\beta-\beta_{2}\right)}}\right)$, with $\delta$ equal to $-0.5 \mathrm{rad}^{-1}$. $\phi_{1} \& \phi_{2}$, and $\lambda_{1} \& \lambda_{2}$ are parameters which determine the northern and southern, and western and eastern edges of the relaxation region, respectively. An example of $f\left(\beta, \beta_{1}, \beta_{2}\right)$ (either latitudinal or longitudinal) is shown in Fig. 14. $\beta_{1}$ and $\beta_{2}$ are the defined boundaries of the relaxation region, and the value of $\gamma_{\max }$ depends on the size of the relaxation region. The size of the relaxation region also determines the overall width of the relaxation tapering band, although $\gamma$ is always 0.5 at the midpoint of each of the relaxation boundaries, $\beta_{1}$ and $\beta_{1}$, and 0.01 about $10^{\circ}$ outside of the boundaries. The example shown in Fig. 14 is for a difference of $20^{\circ}$ between $\beta_{1}$ and $\beta_{1}$, and this gives a value of $\gamma_{\max }$ of 0.99 .

\section{Thermal forcing technique}

The additional heating term, $\mathcal{H}$, used in the thermal forcing experiments is defined as:

$\mathcal{H}=f\left(\phi, \phi_{1}, \phi_{2}\right) f\left(\lambda, \lambda_{1}, \lambda_{2}\right) f\left(Z, Z_{1}, Z_{2}\right)$,

where $f\left(\phi, \phi_{1}, \phi_{2}\right)$ and $f\left(\lambda, \lambda_{1}, \lambda_{2}\right)$ have the same definition as above. Here, $f\left(Z, Z_{1}, Z_{2}\right)$ defines the vertical profile of the heating, and has the following form:

$f\left(Z, Z_{1}, Z_{2}\right)=\left(\frac{1}{1+e^{-\left(Z-Z_{1}\right)}}\right)\left(\frac{1}{1+e^{-0.5\left(Z_{2}-Z\right)}}\right)$

where $Z$ is the level number and $Z_{\min }$ and $Z_{\max }$ are the lower and upper bounds, at which the heating rate is half of the peak value.

The total column integrated heating applied in the thermal forcing experiments was calculated using:

$Q=\frac{c_{p}}{g} \sum H(p) \Delta p$,

where $c_{p}$ is the specific heat capacity of dry air at constant pressure $\left(1004 \mathrm{Jkg}^{-1} \mathrm{~K}^{-1}\right), g$ is the acceleration due to gravity, $\Delta p$ is the pressure difference between model levels and

$H(p)=H_{r} \eta$

Here, $H_{r}$ is the heating rate $\left(0.08 \mathrm{~J} \mathrm{~K}^{-1}\right)$ and $\eta$ is a function of the horizontal and vertical components of the heating profile. The latent heating associated with precipitation ("precipitation flux equivalent", PFE) was calculated using:

$P F E=\rho_{\text {water }} L P$,

where $\rho_{\text {water }}$ is the density of water $\left(1000 \mathrm{~kg} \mathrm{~m}^{-3}\right), L$ is the latent heat of evaporation for water $\left(2.501 \times 10^{6} \mathrm{JKg}^{-1}\right)$ and $P$ is the precipitation rate in $\mathrm{ms}^{-1}$. The total heating in the thermal forcing experiments is therefore calculated as the sum of $Q$ and $P F E$, and in the control is equal to PFE. 
Acknowledgements JDB and SJW were funded by the Natural Environment Research Council (NERC) through the SummerTIME Project (NE/M005909/1). SJW is also supported by the National Centre for Atmospheric Science, a NERC collaborative centre under contract $\mathrm{R} 8 / \mathrm{H} 12 / 83 / 001$. LHB is funded by NERC through the IMPETUS project (NE/L010488/1). This work was supported by the ECMWF Special Project "The Role of the Asian Summer Monsoon as a driver of European Summer Circulation Variability". We also thank the four anonymous reviewers for their constructive comments that helped to improve the manuscript. The datasets analysed during the current study are available from the corresponding author on reasonable request.

Open Access This article is licensed under a Creative Commons Attribution 4.0 International License, which permits use, sharing, adaptation, distribution and reproduction in any medium or format, as long as you give appropriate credit to the original author(s) and the source, provide a link to the Creative Commons licence, and indicate if changes were made. The images or other third party material in this article are included in the article's Creative Commons licence, unless indicated otherwise in a credit line to the material. If material is not included in the article's Creative Commons licence and your intended use is not permitted by statutory regulation or exceeds the permitted use, you will need to obtain permission directly from the copyright holder. To view a copy of this licence, visit http://creativecommons.org/licenses/by/4.0/.

\section{References}

Adler RF, Huffman GJ, Chang A, Ferraro R, Xie PP, Janowiak J, Rudolf B, Schneider U, Curtis S, Bolvin D, Gruber A, Susskind J, Arkin P, Nelkin E (2003) The version-2 global precipitation climatology project (GPCP) monthly precipitation analysis (1979-present). J Hydrometeorol 4(6):1147-1167https://doi.org/ 10.1175/1525-7541(2003)004<1147:TVGPCP > 2.0.CO;2

Balmaseda MA, Mogensen K, Weaver AT (2013) Evaluation of the ECMWF ocean reanalysis system ORAS4. Q J R Meteorol Soc 139(674):1132-1161

Beverley JD, Woolnough SJ, Baker LH, Johnson SJ, Weisheimer A (2019) The northern hemisphere circumglobal teleconnection in a seasonal forecast model and its relationship to European summer forecast skill. Clim Dyn 52(5):3759-3771. https://doi.org/10. 1007/s00382-018-4371-4

Bollasina MA, Messori G (2018) On the link between the subseasonal evolution of the North Atlantic Oscillation and East Asian climate. Clim Dyn 51(9):3537-3557

Branstator G (2014) Long-lived response of the midlatitude circulation and storm tracks to pulses of tropical heating. J Clim 27(23):8809-8826

Chen G, Huang R (2012) Excitation mechanisms of the teleconnection patterns affecting the July precipitation in Northwest China. J Clim 25(22):7834-7851

Dee DP, Uppala SM, Simmons AJ, Berrisford P, Poli P, Kobayashi S, Andrae U, Balmaseda MA, Balsamo G, Bauer P, Bechtold P, Beljaars ACM, van de Berg L, Bidlot J, Bormann N, Delsol C, Dragani R, Fuentes M, Geer AJ, Haimberger L, Healy SB, Hersbach H, Hólm EV, Isaksen L, Kållberg P, Köhler M, Matricardi M, Mcnally AP, Monge-Sanz BM, Morcrette JJ, Park BK, Peubey C, de Rosnay P, Tavolato C, Thépaut JN, Vitart F, (2011) The ERA-interim reanalysis: configuration and performance of the data assimilation system. Q J R Meteorol Soc 137(656):553-597. https://doi.org/10.1002/qj.828
Di Capua G, Kretschmer M, Donner RV, Bvd Hurk, Vellore R, Krishnan R, Coumou D (2020) Tropical and mid-latitude teleconnections interacting with the Indian summer monsoon rainfall: a theory-guided causal effect network approach. Earth Syst Dyn 11(1):17-34

Ding Q, Wang B (2005) Circumglobal teleconnection in the northern hemisphere summer. J Clim 18(17):3483-3505. https://doi.org/ 10.1175/JCLI3473.1

Ding Q, Wang B (2007) Intraseasonal teleconnection between the summer Eurasian wave train and the Indian monsoon. J Clim 20(15):3751-3767

Ding Q, Wang B, Wallace JM, Branstator G (2011) Tropical-extratropical teleconnections in boreal summer: observed interannual variability. J Clim 24(7):1878-1896. https://doi.org/10.1175/ 2011JCLI3621.1

Douville H, Bielli S, Cassou C, Déqué M, Hall NM, Tyteca S, Voldoire A (2011) Tropical influence on boreal summer midlatitude stationary waves. Clim Dyn 37(9-10):1783-1798

Enomoto T, Hoskins BJ, Matsuda Y (2003) The formation mechanism of the Bonin high in August. Q J R Meteorol Soc 129(587):157-178

Ferranti L, Palmer T, Molteni F, Klinker E (1990) Tropical-extratropical interaction associated with the 30-60 day oscillation and its impact on medium and extended range prediction. J Atmos Sci 47(18):2177-2199

Gill A (1980) Some simple solutions for heat-induced tropical circulation. Q J R Meteorol Soc 106(449):447-462

Hong X, Lu R (2016) The meridional displacement of the summer Asian jet, Silk Road Pattern, and tropical SST anomalies. J Clim 29(10):3753-3766

Hoskins BJ, Ambrizzi T (1993) Rossby wave propagation on a realistic longitudinally varying flow. J Atmos Sci 50(12):1661-1671

Johnson SJ, Turner A, Woolnough S, Martin G, MacLachlan C (2016) An assessment of Indian monsoon seasonal forecasts and mechanisms underlying monsoon interannual variability in the met office GloSea5-GC2 System. Clim Dyn 1-19

Johnson SJ, Stockdale TN, Ferranti L, Balmaseda MA, Molteni F, Magnusson L, Tietsche S, Decremer D, Weisheimer A, Balsamo G, Keeley SPE, Mogensen K, Zuo H, Monge-Sanz BM (2019) SEAS5: the new ECMWF seasonal forecast system. Geosci Model Dev 12(3):1087-1117

Jung T, Miller M, Palmer T (2010a) Diagnosing the origin of extended-range forecast errors. Mon Weather Rev 138(6):2434-2446

Jung T, Palmer T, Rodwell M, Serrar S (2010b) Understanding the anomalously cold European winter of 2005/06 using relaxation experiments. Mon Weather Rev 138(8):3157-3174

Klinker E (1990) Investigation of systematic errors by relaxation experiments. Q J R Meteorol Soc 116(493):573-594

Kosaka Y, Chowdary J, Xie SP, Min YM, Lee JY (2012) Limitations of seasonal predictability for summer climate over East Asia and the Northwestern Pacific. J Clim 25(21):7574-7589

Lau KM, Weng H (2002) Recurrent teleconnection patterns linking summertime precipitation variability over East Asia and North America. J Meteorol Soc Jpn 80(6):1309-1324

Lau WKM, Kim KM, Lee JY (2004) Interannual variability, global teleconnection, and potential predictability associated with the Asian summer monsoon. In: Chang CP (ed) East Asian Monsoon. World Scientific, New York, pp 153-176

Li C, Jia X, Ling J, Zhou W, Zhang C (2009) Sensitivity of MJO simulations to diabatic heating profiles. Clim Dyn 32(2-3):167-187

Liu F, Wang B (2013) Mechanisms of global teleconnections associated with the Asian summer monsoon: an intermediate model analysis. J Clim 26(5):1791-1806 
Lu RY, Oh JH, Kim BJ (2002) A teleconnection pattern in upper-level meridional wind over the North African and Eurasian continent in summer. Tellus A 54(1):44-55

Molteni F, Stockdale T, Balmaseda M, Balsamo G, Buizza R, Ferranti L, Magnusson L, Mogensen K, Palmer T, Vitart F (2011) The new ECMWF seasonal forecast system (System 4). European Centre for Medium-Range Weather Forecasts

OReilly CH, Woollings T, Zanna L, Weisheimer A (2018) The impact of tropical precipitation on summertime Euro-Atlantic circulation via a circumglobal wave-train. J Clim 31:6481-504

Rodwell MJ, Hoskins BJ (1996) Monsoons and the dynamics of deserts. Q J R Meteorol Soc 122(534):1385-1404. https://doi. org/10.1002/qj.49712253408

Sardeshmukh PD, Hoskins BJ (1988) The generation of global rotational flow by steady idealized tropical divergence. J Atmos Sci 45(7):1228-1251

Schumacher C, Houze RA Jr, Kraucunas I (2004) The tropical dynamical response to latent heating estimates derived from the TRMM precipitation radar. J Atmos Sci 61(12):1341-1358

Shaman J (2014) The seasonal effects of ENSO on atmospheric conditions associated with European precipitation: model simulations of seasonal teleconnections. J Clim 27(3):1010-1028
Shaman J, Tziperman E (2007) Summertime ENSO-North AfricanAsian Jet teleconnection and implications for the Indian monsoons. Geophys Res Lett 34(11):1-7

Stephan CC, Klingaman NP, Turner AG (2019) A mechanism for the recently increased interdecadal variability of the Silk Road Pattern. J Clim 32(3):717-736

Wang B, Wu R, Lau K (2001) Interannual variability of the Asian summer monsoon: contrasts between the Indian and the western North Pacific-East Asian monsoons. J Clim 14(20):4073-4090

Watson PA, Weisheimer A, Knight JR, Palmer T (2016) The role of the tropical West Pacific in the extreme Northern Hemisphere winter of 2013/2014. J Geophys Res Atmos 121(4):1698-1714

Wilks DS (2011) Statistical methods in the atmospheric sciences, vol 100. Academic press, New York

Wu R, Wang B (2002) A contrast of the East Asian summer monsoon-ENSO relationship between 1962-77 and 1978-93. J Clim 15(22):3266-3279

Publisher's Note Springer Nature remains neutral with regard to jurisdictional claims in published maps and institutional affiliations. 